\title{
Catalytic partial oxidation of methyl acetate as a model to investigate the conversion of methyl esters to hydrogen
}

\author{
Betty Ngoc Thy Nguyen \\ Department of Chemical Engineering \\ McGill University, Montreal
}

February 2007

A thesis submitted to McGill University in partial fulfilment of the requirements of the degree of Master in Chemical Engineering

๑) Betty Ngoc Thy Nguyen, 2007 


$\begin{array}{ll}\begin{array}{l}\text { Library and } \\ \text { Archives Canada }\end{array} & \begin{array}{l}\text { Bibliothèque et } \\ \text { Archives Canada }\end{array} \\ \begin{array}{l}\text { Published Heritage } \\ \text { Branch }\end{array} & \begin{array}{l}\text { Direction du } \\ \text { Patrimoine de l'édition }\end{array} \\ \begin{array}{l}\text { 395 Wellington Street } \\ \text { Ottawa ON K1A 0N4 }\end{array} & \begin{array}{l}\text { 395, rue Wellington } \\ \text { Ottawa ON K1A ON4 } \\ \text { Canada }\end{array} \\ \end{array}$

Your file Votre référence ISBN: 978-0-494-32611-4 Ourfile Notre référence ISBN: 978-0-494-32611-4

NOTICE:

The author has granted a nonexclusive license allowing Library and Archives Canada to reproduce, publish, archive, preserve, conserve, communicate to the public by telecommunication or on the Internet, loan, distribute and sell theses worldwide, for commercial or noncommercial purposes, in microform, paper, electronic and/or any other formats.

The author retains copyright ownership and moral rights in this thesis. Neither the thesis nor substantial extracts from it may be printed or otherwise reproduced without the author's permission.
AVIS:

L'auteur a accordé une licence non exclusive permettant à la Bibliothèque et Archives Canada de reproduire, publier, archiver, sauvegarder, conserver, transmettre au public par télécommunication ou par l'Internet, prêter, distribuer et vendre des thèses partout dans le monde, à des fins commerciales ou autres, sur support microforme, papier, électronique et/ou autres formats.

L'auteur conserve la propriété du droit d'auteur et des droits moraux qui protège cette thèse. $\mathrm{Ni}$ la thèse ni des extraits substantiels de celle-ci ne doivent être imprimés ou autrement reproduits sans son autorisation.
In compliance with the Canadian

Privacy Act some supporting forms may have been removed from this thesis.

While these forms may be included in the document page count, their removal does not represent any loss of content from the thesis.
Conformément à la loi canadienne sur la protection de la vie privée, quelques formulaires secondaires ont été enlevés de cette thèse.

Bien que ces formulaires aient inclus dans la pagination, il n'y aura aucun contenu manquant. 


\section{Abstract}

Rhodium, platinum, copper, palladium, and rhodium-ceria catalysts were investigated in the catalytic partial oxidation of methyl acetate, the simplest methyl ester, to better understand the conversion of biodiesel to hydrogen. Only rhodium and rhodium-ceria catalysts allowed for an autothermal reactor operation. Both catalysts were active in producing hydrogen, carbon monoxide, water, and carbon dioxide, although the rhodium-ceria catalyst showed the greater methyl acetate conversion and the greater hydrogen and carbon monoxide selectivities. A low $\mathrm{C} / \mathrm{O}$ feed ratio favored the methyl acetate conversion, the hydrogen selectivity, and the carbon monoxide selectivity. Furthermore, a high gas hourly space velocity also improved the reactor performance. According to the experimental data, it appears that the oxidation of methyl acetate forms carbon monoxide and water as a primary step, instead of carbon dioxide and water as with the combustion reaction. In general, methyl acetate does not yield more synthesis gas than biodiesel. The methyl ester functional group limits the hydrogen yield and hence new catalysts should be developed and investigated in order to better target the decomposition of methyl esters to hydrogen. 


\section{Résumé}

Le rhodium, le platine, le cuivre, le palladium et le rhodium-cérium ont été évalués pour leur activité catalytique pour l'oxydation partielle catalytique de l'acétate de méthyle. L'acétate de méthyle est l'ester de méthyle le plus simple et il est utilisé dans ce procédé afin de mieux comprendre la conversion du biodiesel à l'hydrogène. Parmi ces catalyseurs, seulement le rhodium et le rhodium-cérium ont permis d'opérer le réacteur en mode autothermique. Les deux catalyseurs ont démontré une bonne conversion de l'acétate de méthyle et une sélectivité envers l'hydrogène et le monoxyde de carbone. Le rhodiumcérium a engendré une conversion et une sélectivité accrues comparativement au rhodium seul. Un faible rapport carbone/oxygène dans l'alimentation du réacteur a favorisé la conversion de l'acétate de méthyle, la sélectivité envers l'hydrogène et la sélectivité envers le monoxyde de carbone. II en est aussi de même pour un haut débit de gaz d'alimentation. Selon les données expérimentales, les produits intermédiaires formés au cours de la première étape de l'oxydation partielle de l'acétate de méthyle sont le monoxyde de carbone et l'eau plutôt que du dioxyde carbone et l'eau lors d'une combustion. La conversion de l'acétate de methyle a produit moins de gaz de synthèse que le biodiesel. Le groupe fonctionnel de l'ester de méthyle limite ici le rendement d'hydrogène et par conséquent, de nouveaux catalyseurs doivent être développés et évalués pour mieux optimiser la décomposition des esters de méthyle en hydrogène. 


\section{Table of Contents}

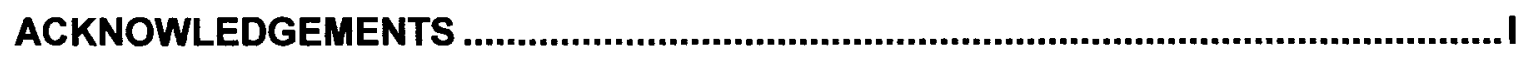

INTRODUCTION ...................................................................................................

OBJECTIVES...........................................................................................................5

BACKGROUND .................................................................................................. 6

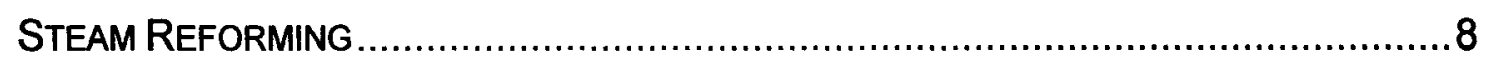

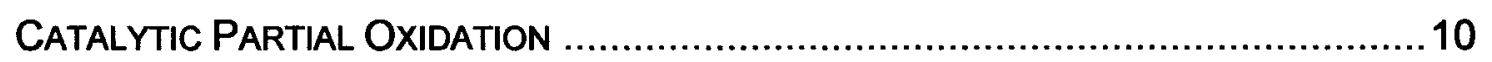

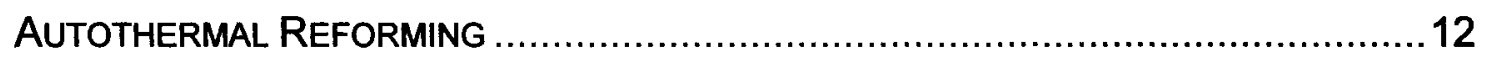

LITERATURE REVIEW........................................................................................ 14

Catalytic Partial Oxidation of Alkanes .......................................... 14

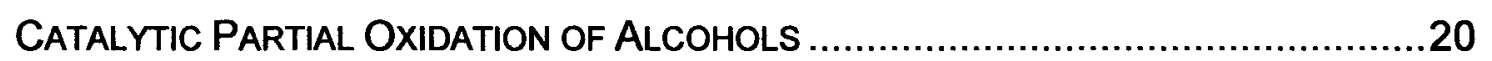

Catalytic Partial Oxidation of Biodiesel.............................................. 22

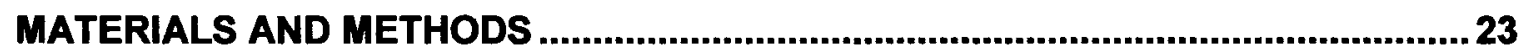

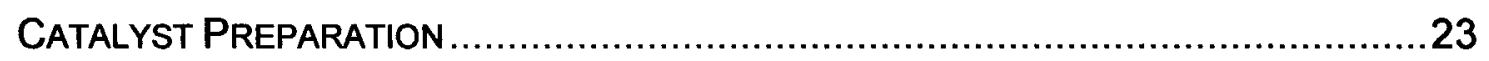

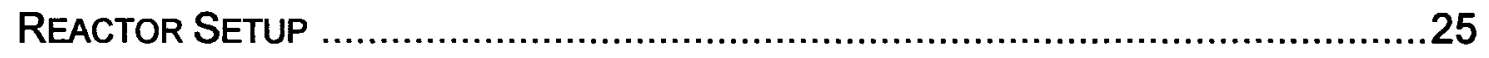

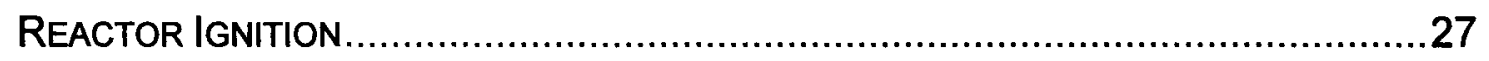

DATA ACQUISITION AND PROCESS CONTROL ........................................ 27

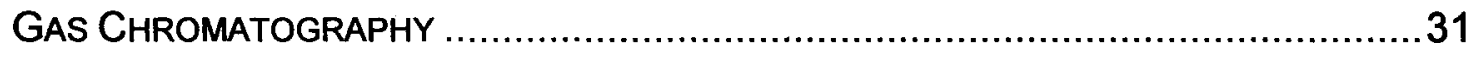

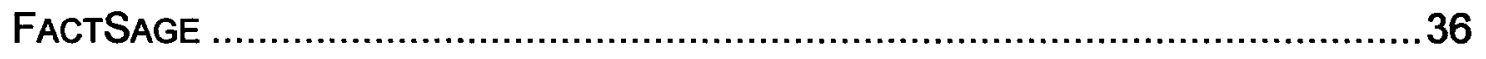


ReActor PARAMETERS AND PERformanCE CRITERIA ................................. 37

RESULTS ........................................................................................................ 41

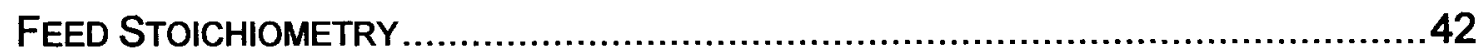

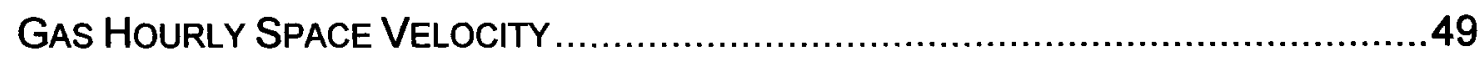

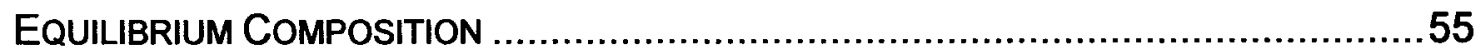

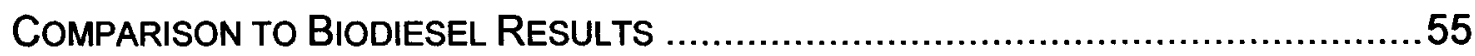

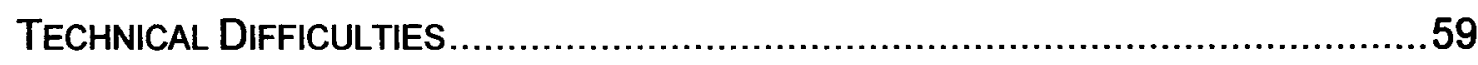

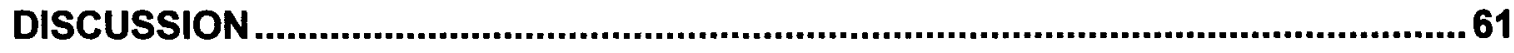

RHODIUM VERSUS RHODIUM-CERIA .................................................61

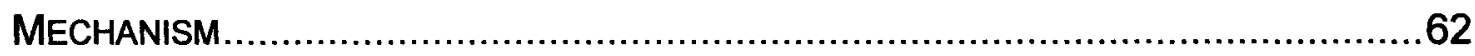

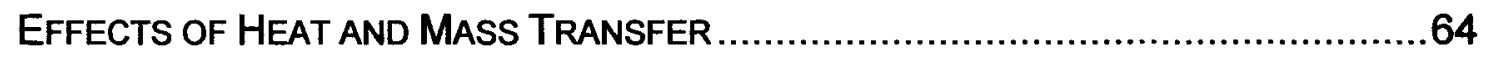

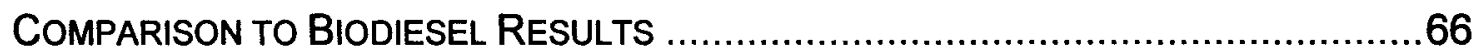

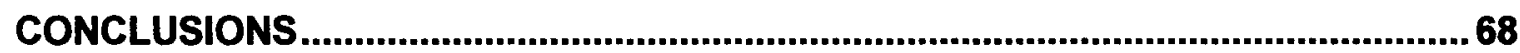

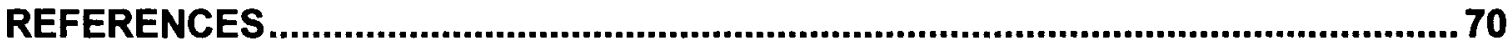

APPENDIX I: FUEL INJECTOR CALIBRATION CURVE ........................................ 78

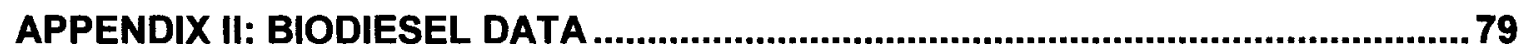




\section{Table of Figures}

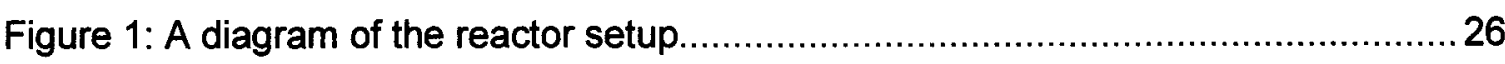

Figure 2: Response of the back face temperature of the Rh and RhCe catalysts ........ 43

Figure 3: Response of the oxygen conversion $\left(\mathrm{X}_{\mathrm{O}_{2}}\right)$ of the Rh and RhCe catalysts with respect to the $\mathrm{C} / \mathrm{O}$ ratio

Figure 4: Response of the methyl acetate conversion $\left(X_{M A}\right)$ of the Rh and RhCe catalysts with respect to the $\mathrm{C} / \mathrm{O}$ feed ratio.

Figure 5: Response of the hydrogen selectivity $\left(\mathrm{S}_{\mathrm{H} 2}\right)$ of the $\mathrm{Rh}$ and $\mathrm{RhCe}$ catalysts with respect to the $\mathrm{C} / \mathrm{O}$ feed ratio

Figure 6: Response of the water selectivity $\left(\mathrm{S}_{\mathrm{H} 2 \mathrm{O}}\right)$ of the Rh and RhCe catalysts with respect to the $\mathrm{C} / \mathrm{O}$ ratio

Figure 7: Response of the carbon monoxide selectivity $\left(S_{\mathrm{co}}\right)$ of the $\mathrm{Rh}$ and $\mathrm{RhCe}$ catalysts with respect to the $\mathrm{C} / \mathrm{O}$ ratio

Figure 8: Response of the carbon dioxide selectivity $\left(\mathrm{S}_{\mathrm{CO} 2}\right)$ of the Rh and RhCe catalysts with the respect to the $\mathrm{C} / \mathrm{O}$ ratio. 48

Figure 9:Response of the back face temperature with respect to the GHSV 50

Figure 10: Response of the oxygen conversion $\left(X_{\mathrm{O}_{2}}\right)$ with respect to the GHSV 51

Figure 11: Response of the methyl acetate conversion $\left(X_{M A}\right)$ with respect to the GHSV 51

Figure 12: Response of the hydrogen selectivity $\left(\mathrm{S}_{\mathrm{H} 2}\right)$ with respect to the GHSV .52

Figure 13: Response of the water selectivity $\left(\mathrm{S}_{\mathrm{H} 2 \mathrm{O}}\right)$ with respect to the GHSV 53

Figure 14: Response of the carbon monoxide selectivity $\left(S_{c o}\right)$ with respect to the GHSV

Figure 15: Effect of the carbon dioxide selectivity $\left(\mathrm{S}_{\mathrm{CO} 2}\right)$ with respect to the GHSV 54 
Figure 16: Methyl acetate conversion $\left(X_{M A}\right)$ versus $C / O$ ratio.

Figure 17: Hydrogen selectivity $\left(\mathrm{S}_{\mathrm{H} 2}\right)$ versus $\mathrm{C} / \mathrm{O}$ ratio

Figure 18: Water selectivity $\left(\mathrm{S}_{\mathrm{H} 2 \mathrm{O}}\right)$ versus $\mathrm{C} / \mathrm{O}$ ratio 57

Figure 19: Carbon monoxide selectivity $\left(\mathrm{S}_{\mathrm{CO}}\right)$ versus $\mathrm{C} / \mathrm{O}$ ratio 58

Figure 20: Carbon dioxide selectivity $\left(\mathrm{S}_{\mathrm{CO} 2}\right)$ versus $\mathrm{C} / \mathrm{O}$ ratio 58 


\section{Acknowledgements}

The author would like to thank the Eugénie Ulmer Lamothe (E.U.L.) Fund for financial support, Prof. Corey Leclerc for advising and guidance in this work, Ranjan Roy for his expertise and assistance with gas chromatography, Gerald Lepkyj and Luciano Cusmich for their expertise and assistance with electronic devices for process control and data acquisition, Frank Caporuscio for assistance with the apparatus setup, Prof. Viviane Yargeau for assistance with the translation of the thesis abstract, and Annie Nguyen for editorial help. 


\section{Introduction}

Our present society consumes vast amounts of energy derived from nonrenewable resources such as petroleum. As such resources are being gradually depleted, the cost of their use increases and will slowly become economically non-viable. In addition, the production of energy through the combustion of the non-renewable fuels releases considerable amounts of pollutants such as greenhouse gases and acid rain-causing compounds into the environment. These problems constitute an incentive to develop and optimize alternative means of energy production.

The current research on alternative means of energy production focuses on two possible solutions to replace the combustion of fossil fuels: either an alternative fuel to be used in the energy production process, or an alternative process to combustion to extract the energy. The production of energy from renewable fuels does not permanently deplete the natural resources. Furthermore, the use of biomass-derived fuels would result in a reduction in net emissions of greenhouse gases (carbon monoxide and carbon dioxide). The carbon dioxide produced would re-enter the carbon cycle through photosynthesis by plants responsible for producing the biomass necessary to make the fuel in the first place. Hence an alternative renewable fuel is desired to lessen the emissions of gases responsible for global warming. Moreover, the use of an alternative process to combustion 
would reduce the formation of acid rain-causing compounds such as nitrogen oxides (NOx), sulfur oxides, and sulfuric acid. Nitrous oxides are formed when the nitrogen in the engine's intake air reacts at high combustion temperatures while sulfur oxides and sulfuric acid formation is caused by the presence of sulfur in the fuel. Also, there are considerable amounts of greenhouse gases produced through complete and incomplete combustion of fossil fuels [1]. It is therefore preferable to develop and perfect alternative processes which would extract energy from the fuel with a lesser environmental impact.

An example of an alternative means of energy production is the fuel cell technology. Fuel cells effectively convert chemical energy (i.e. energy stored in chemical compounds) into electrical energy. Most low temperature fuel cells (with the exception of the direct methanol fuel cell) use hydrogen as fuel and the major product of the total cell redox reaction is water. The low operating temperature of the fuel cells prevent the formation of NOx, which are highly reactive pollutants responsible for acid rains among other health and environmental concerns [2, 3].

Synthesis gas or syngas is a good source of hydrogen for fuel cells, since it is a mixture of hydrogen and carbon monoxide in a 2:1 molar ratio. Most of the hydrogen production is currently done through the steam reforming (SR) of natural gas [4]. With SR being an endothermic process, the catalytic partial 
oxidation (CPO) would be the preferred means of producing synthesis gas as it is an exothermic, two-step process. Also, the contact times for CPO are less than those for SR by 2 to 3 orders of magnitude, which allows for greater throughput [5-7]. The most commonly studied reactants used for CPO are alkanes (methane, ethane, hexane, ...) and alcohols (methanol, ethanol, propanol, ...). Although studies have shown that alkanes are effectively converted into syngas through CPO, alkanes originate mostly from petroleum refining processes and hence they do not constitute a renewable source of energy. Conversely, alcohols may be produced through petroleum processing but some alcohols may be derived from biomass such as crop waste, starch, and sugar $[8,9]$. A recent study has shown that under certain operating conditions for a CPO reactor, biodiesel was converted to hydrogen and carbon monoxide in appreciable selectivities [10]. As biodiesel is a biomass-derived fuel, its potential use for syngas production would be highly beneficial if its hydrogen would be used in fuel cells for energy production.

Biodiesel is a mixture of alkyl esters resulting from the transesterification of triglycerides or free fatty acids with an alcohol in the presence of a catalyst [11]. Because of this production method, the ester molecule can be set as the combination of two functional groups: the fatty acid group and the alcohol group. Since the CPO of ester molecules is not yet well understood as it is the case with alkanes and alcohols, it is necessary to isolate each functional group in order to 
better investigate the reaction.

This work uses methyl acetate as a simplified version of biodiesel and focuses on the study of its autothermal catalytic partial oxidation. Several noble and transition metals supported on an alumina foam monolith are evaluated for their catalytic activity for syngas production. 


\section{Objectives}

The main objective of this thesis is to investigate the autothermal catalytic partial oxidation of methyl acetate. The specific objectives of the research are:

- To evaluate the suitability of various noble and transition metals (rhodium, platinum, copper, palladium, and rhodium-ceria) as catalysts for the partial oxidation reaction

- To study the effect of the methyl acetate to oxygen feed ratio and of the gas hourly space velocity on the product selectivities and fuel conversion

- To compare the results to that of the catalytic partial oxidation of biodiesel

The thesis is separated into 4 parts. The first two sections of the thesis will provide thorough background information on the research subject and an extensive literature review on the work previously done on the catalytic partial oxidation process. This will be followed by a description and explanation of the experimental setup and procedure and the results will be presented and discussed towards the end. 


\section{Background}

Fuel cells are electrochemical devices that generate power by converting the chemical energy stored in fuels into electrical energy. The fuel cells' lack of heat and mechanical work generation implies that they are not limited by the thermodynamics of the conventional heat engines. As a result, they can produce power at a greater efficiency: fuel cells have efficiencies ranging from $35 \%$ to $65 \%$ while reciprocating engines exhibit efficiencies around 33-37\% [12]. Furthermore, fuel cells have a smaller environmental impact because they do not use combustion to produce the power from the fuel. Since combustion is not the power generating reaction, the fuel cells' operating temperature range is much lower than that of an internal combustion engine. With all fuel cell types confounded, the operating temperatures range from $40^{\circ} \mathrm{C}$ to $1000^{\circ} \mathrm{C}$ [12] while NOx formation becomes significant above $1500^{\circ} \mathrm{C}$ [13].

There are many types of fuel cells; the most common classification is done as per

the type of electrolyte used. Also, the fuel cells' operating temperature can also be used to classify the fuel cells on a broader level. The low temperature fuels include the polymer electrolyte membrane fuel cell (PEMFC), the direct methanol fuel cell (DMFC), the alkaline fuel cell (AFC), and the phosphoric acid fuel cell (PAFC). These fuels cells used aqueous electrolytes and as a result of the vapor pressures of the electrolytes their maximum operating temperature is about 
$200^{\circ} \mathrm{C}$. In addition, the fact that platinum is used as catalyst for those fuels cells makes them prone to carbon monoxide $(\mathrm{CO})$ poisoning, implying that the fuel used must be processed so as to have as little contaminants as possible. On the other hand, the high temperature fuel cells, which include the molten carbonate fuel cell (MCFC) and the solid oxide fuel cell (SOFC), use the carbon monoxide as a fuel. They hence do not require as much fuel processing since at operating temperatures up to $1000^{\circ} \mathrm{C}$, they can even convert methane from the fuel into hydrogen or directly oxidize it electrochemically [12].

The fuel used for the existing fuel cells is either gaseous hydrogen or a hydrogenrich gas mixture such as synthesis gas. Hydrogen readily undergoes oxidation reactions and it can be produced from a wide variety of fuels. Depending on the nature of the fuel and on the type of fuel cell, there are different steps of fuel processing needed. Most fuel cells are sensitive to sulfur poisoning and therefore a sulfur removal unit is necessary if fossil fuels are used to supply the hydrogen. With low temperature fuel cells, it is crucial to have a hydrogen feed stream of very high purity, free of carbon monoxide and carbon dioxide. Since the conversion step of the fuel into hydrogen yields a product stream, which also contains carbon monoxide, carbon dioxide, and water. A water-gas shift reactor is needed to further process the stream and optimize the hydrogen yield before the purification process. In the case of high temperature fuel cells, there are not as many purification processes required since carbon monoxide is then taken as a 
fuel and carbon dioxide is considered a diluent [12].

Synthesis gas is the main source of hydrogen for fuel cells, even though it can be used directly into high temperature fuel cells for reasons explained earlier. It can also be used for other applications. For instance, syngas can be converted into larger organic compounds through the Fisher-Tropsch synthesis. The process consists of reacting the hydrogen and carbon monoxide mixture over a transition metal catalyst at elevated temperatures and pressures. The product of the synthesis is a mixture of large hydrocarbons and oxygenated compounds. In addition to the Fisher-Tropsch process, synthesis gas constitutes a feedstock for the production of methanol and higher alcohols[14].

\section{Steam Reforming}

The industrial process conventionally used for synthesis gas production is the steam reforming of methane. Methane and steam are reacted over a nickelbased catalyst, giving to the formation of carbon monoxide and hydrogen. The overall reaction is as follows:

$$
\mathrm{CH}_{4}+\mathrm{H}_{2} \mathrm{O} \leftrightarrow \mathrm{CO}+3 \mathrm{H}_{2} \quad \Delta \mathrm{H}^{\circ}=+205.8 \mathrm{~kJ} / \mathrm{mol}
$$

The process is usually operated in excess steam, with a steam to carbon ratio between 2 and 4 . Due to the reaction's endothermicity, an external heat input is 
necessary to maintain the reactor's operation. This is usually done with the implementation of an adjacent furnace. The fact that the water-gas shift reaction (2) also occurs in the steam reformer will affect the equilibrium composition, as it can further convert some of the carbon monoxide and hydrogen into carbon dioxide and water:

$$
\mathrm{CO}+\mathrm{H}_{2} \mathrm{O} \leftrightarrow \mathrm{CO}_{2}+\mathrm{H}_{2} \quad \Delta \mathrm{H}^{\circ}=-41.2 \mathrm{~kJ} / \mathrm{mol}
$$

The product composition will depend on the reformer's operating temperature and pressure. At higher temperatures, the carbon monoxide yield is higher while the product stream's carbon dioxide and methane contents are lower. However, an increase in operating pressure will cause the methane and water conversion to drop significantly $[5,12,15]$.

Since various parts in the world do not have ready access to methane, the steam reforming process has also been researched and developed for light petroleum naphthas and other organic compounds. For instance, Rioche et al. have shown that rhodium supported on alumina or ceria-zirconia and platinum supported on ceria-zirconia exhibit good catalytic activity for syngas formation through the steam reforming of acetic acid and acetone. They have also reported that the steam reforming of ethanol over rhodium on a ceria-zirconia support converted ethanol into synthesis gas components [6]. Also, it was found that the steam reforming of propane in micro-channels over a catalytic mixture of rhodium and 
platinum on a ceria support results in satisfactory yields of hydrogen [16]. For any organic fuel, the overall steam reforming reaction is written below:

$\mathrm{C}_{n} \mathrm{H}_{m} \mathrm{O}_{k}+(n-k) \mathrm{H}_{2} \mathrm{O} \leftrightarrow n \mathrm{CO}+(m / 2+n-k) \mathrm{H}_{2}$

There are various disadvantages to the use of steam reforming to produce synthesis gas components. First, the typical contact time for a steam reformer is on the order of 1 second. Hence a steam reformer must be large in size in order to produce synthesis gas at the industrial scale $[17,18]$. Also, the endothermicity of the steam reforming reaction implies that external heat input is necessary to maintain the reactor at the steam reformer's operating temperatures. Those temperatures can vary between $750^{\circ} \mathrm{C}$ and $900^{\circ} \mathrm{C}$. The usual means of heat input to the steam reformer consist of an adjacent furnace, which would then inevitably implicate heat losses due to the heat generation in the furnace and its transfer to

the reactor $[12,19]$. Furthermore, the operation of a steam reformer is usually at high pressures in addition to the high temperatures. With the high steam to carbon ratios typically used, thermodynamics indicate that the equilibriated product gas may undergo carbon formation, hence deactivating the catalyst [19].

\section{Catalytic Partial Oxidation}

Catalytic partial oxidation has been studied during the last 15 years as an alternative means of synthesis gas production to steam reforming. The process consists of reacting the organic fuel with oxygen over an active catalytic metal 
supported on a porous ceramic monolith $[15,18]$. The oxygen may be introduced in the reactor as a pure gaseous component or in a diluted form as in air. The reactor is operated in autothermal, fuel-rich conditions. The overall reaction is as follows.

$\mathrm{C}_{\mathrm{n}} \mathrm{H}_{\mathrm{m}} \mathrm{O}_{\mathrm{k}}+(\mathrm{n}-\mathrm{k}) / 2 \mathrm{O}_{2} \rightarrow \mathrm{n} \mathrm{CO}+(\mathrm{m} / 2) \mathrm{H}_{2}$

Research has shown that a great variety of fuels can undergo catalytic partial oxidation to produce synthesis gas components. The reactant used can be an alkane (methane, ethane, propane, n-butane, n-hexane, n-octane, decane, $n$ hexadecane ) $[7,17,18,20-29]$, an alcohol (methanol, ethanol, 1-propanol, 2propanol...) [9, 30-33], or more complex organic compounds such as biodiesel [34]. Since the atomic carbon to oxygen $(\mathrm{C} / \mathrm{O})$ ratio is 1.0 for a $2: 1$ syngas mixture, it is desirable to operate the reactor with a feed stoichiometry close to that ratio. For most fuels, the partial oxidation reaction is slightly exothermic and hence the reactor can supply its own heat and operate in an autothermal mode once the catalyst has ignited. In the cases of other fuels such as ethanol, the reaction is slightly endothermic and as a result, a small amount of excess oxygen is introduced into the reactor. This will allow for some combustion to occur in the reactor and the heat released by the combustion will compensate for the endothermicity of the partial oxidation reaction [31]. Literature shows that high conversions and product selectivities can be achieved at reactor contact times on the order of milliseconds $[17,24]$. Moreover, it was demonstrated that the partial oxidation reactor can be started up from room temperature in a very short amount 
of time, compared to the steam reformer [35]. These characteristics of the catalytic partial oxidation reaction indicate that synthesis gas may be produced in a small, high-throughput reactor operated autothermally with various fuels, with very small startup times. However, the hydrogen yield is lower than that for steam reforming due the lack of steam addition into the reactor.

\section{Autothermal Reforming}

The combination of catalytic partial oxidation and steam reforming is known as autothermal reforming. In this reaction, either oxygen or air along with steam are introduced and mixed with the fuel. Since partial oxidation is the faster reaction, it occurs at the entrance region of the catalyst. Hence all the dioxygen in the feed is depleted and the heat released from the partial oxidation is conveyed to the downstream section of the catalyst, where it will supply the heat requirements of steam reforming [15]. The reactor is autothermal as with the catalytic partial oxidation and the hydrogen yield is improved by the steam addition [36].

As it was the case with steam reforming and catalytic partial oxidation, the reaction has been investigated for various fuels. Most of them were studied since they had already proven to yield good conversion and product selectivities: methane, methanol, ethanol, n-heptane, n-octane, diesel, biodiesel, n-decane, nhexadecane, JP-8, biodiesel $[8,34,37-40]$. Despite the improved hydrogen 
and the exothermicity of the overall reaction, the steam addition does result in the dilution of the reactants and therefore this will result in a lower reactor temperature [39]. 


\section{Literature Review}

This section is a summary of the literature pertaining to the study and optimization of the catalytic partial oxidation of various fuels. This general overview is subdivided as per the nature of the fuel used for the reaction.

\section{Catalytic Partial Oxidation of Alkanes}

\section{Methane}

The most studied fuel for syngas production by catalytic partial oxidation is methane, as it is the main component of natural gas. For a large number of countries, natural gas is abundant and it is readily available for consumption through the existing infrastructure $[41,42]$. There have been extensive studies on the catalytic partial oxidation of methane. The catalytic metal, the support material, the addition of a washcoat, the effect of the feed stoichiometry, the effect of a preheat temperature, the use of pure oxygen, and the effect of the reactor's gas hourly space velocity have been investigated. The mechanism of the reaction has also been investigated.

Several aspects concerning the catalyst have been investigated: the catalytic metal, the catalytic metal loading, the catalyst's support material, the catalyst 
pore size, and the presence of washcoat. Hickman et al. have studied and compared the catalytic partial oxidation of methane over rhodium (Rh) and platinum (Pt) catalysts supported on alumina foam monoliths. They have shown that rhodium is a significantly better catalyst for the reaction than platinum, yielding greater methane conversions and hydrogen selectivities $[7,17,18]$. Torniainen et al. investigated the catalytic partial oxidation of methane with pure oxygen over other catalytic metals in addition to rhodium and platinum. These included nickel, iridium, palladium, palladium-lanthanium oxide, iron, cobalt, ruthenium, and rhenium. All were supported on alumina foam monoliths. They reported that rhodium and nickel gave the best methane conversion and the better hydrogen and carbon monoxide selectivities, although nickel deactivated by metal loss and volatilization. Rhodium showed no loss in catalytic activity over several hours of operation. Platinum and iridium were stable catalysts but yielded lower conversion and selectivities. The remainder of the metals either deactivated quickly or would not sustain the autothermal reactor operation. The deactivation of the catalytic metal occurred either by metal loss, volatilization, or carbon formation [27]. Moreover, Bodke et al. studied the effect of the catalyst's support material, of the catalytic metal loading, of the catalyst's pore size, and of the presence of a washcoat on the monolith. Several support materials in the form of foam monoliths were examined: $\alpha$-alumina, mullite, zirconia, zirconia-tetraalumina, oxide-bonded silicon carbide, cordierite, and lithium aluminum silicate. The cordierite and lithium aluminum silicate were proven to be unsuitable support materials since they cannot withstand temperatures over $1000^{\circ} \mathrm{C}$. It was then 
shown that rhodium supported on a zirconia foam monolith gave better hydrogen and carbon monoxide selectivities than alumina while tolerating temperatures up to $2000^{\circ} \mathrm{C}$. Furthermore, it was found that a change in catalytic metal loading between $1 \mathrm{wt} \%$ and $10 \mathrm{wt} \%$ had only a small effect on the reactor performance. The pore size experiments were done with alumina monoliths as support materials, with pore sizes varying between 20 pores per inch (ppi) and $80 \mathrm{ppi}$. It was also demonstrated that the use of a catalyst with a smaller pore size resulted in better methane conversion and hydrogen and carbon monoxide selectivities. Lastly, the addition of a $\gamma$-alumina washcoat to an alumina foam monolith before the catalytic metal impregnation was shown to roughen the surface of the support material and to increase the surface area of the catalytic metal, which is subsequently deposited onto the support material. The rougher support material's surface is believed to increase the mixing in the reactant gases, hence improving the hydrogen and carbon monoxide yields [25].

In addition to all the catalyst's characteristics, several parameters regarding the reactor operation were also studied. The effects of the use of pure oxygen, of the preheat temperature, of the feed stoichiometry, and of the reactor's gas hourly space velocity were all assessed. Hickman and Schmidt have shown in their experiments with the catalytic partial oxidation of methane over $\mathrm{Pt}$ monoliths that preheating the reactants to a high feed temperature gives an increase in hydrogen and carbon monoxide selectivity. They have also observed that an 
increase in gas hourly space velocity (GHSV) causes a decrease in contact times and an improvement in reactor performance, as a result of a greater heat transfer rate [18]. However, it was shown in a later paper that this effect is constrained by a mass transfer limitation. As the GHSV is increased, the contact times decrease and at some point the contact time will become too small for the reactant molecules to reach the catalyst's surface [43]. In a more recent publication, Hickman et al. determined that the use of pure $\mathrm{O}_{2}$ in the reactor feed instead of air as the source of oxygen is equivalent to preheating the reactant gases and therefore causes an increase in hydrogen and carbon monoxide selectivities. Also, they noticed that the feed composition for optimal synthesis gas production is slightly lower than the stoichiometric composition [7].

Furthermore, the mechanism of the catalytic partial oxidation of methane over rhodium catalysts was proposed by Buyevskaya et al. Their experiments led to the proposition of a two-step mechanism for the reaction. The methane first undergoes a complete combustion to carbon dioxide and water (5). This will deplete all the oxygen molecules present in the feed. Since the reactor is operated in fuel-rich conditions, there will be methane left over from the primary reaction. The excess methane will then go through reforming reactions with the carbon dioxide (6) and water (7) formed in the first oxidation step, thus producing hydrogen and carbon monoxide [29]. 


$$
\begin{aligned}
& \mathrm{CH}_{4}+2 \mathrm{O}_{2} \rightarrow \mathrm{CO}_{2}+2 \mathrm{H}_{2} \mathrm{O} \\
& \mathrm{CH}_{4}+\mathrm{CO}_{2} \rightarrow 2 \mathrm{H}_{2}+2 \mathrm{CO} \\
& \mathrm{CH}_{4}+\mathrm{H}_{2} \mathrm{O} \rightarrow 3 \mathrm{H}_{2}+\mathrm{CO}
\end{aligned}
$$

As it was demonstrated that the catalytic partial oxidation reaction occurs in two steps, it is then possible to optimize the final product yield by selecting the best catalytic metal for each step reaction. Tong et al. have found that the use of a dual bed, platinum-nickel catalyst generates comparable methane conversion and hydrogen and carbon monoxide selectivities to those seen with a rhodium catalyst. As a result of this finding, the cost of a catalytic partial oxidation catalyst can be reduced by $60 \%$ without much impact on the product yield [5]. Additionally, the dual bed catalyst configuration was revisited with the substitution of the platinum combustion catalyst for various metal oxides catalyst. It was found that copper oxides, chromium oxides, and manganese oxides constitute stable combustion catalysts to be used in combination with a nickel reforming catalyst for similar hydrogen yields to the platinum-nickel catalyst [43].

\section{Higher Alkanes}

In addition to methane, the catalytic partial oxidation of several larger alkanes over catalytic metals supported on alumina foam monoliths was studied. Studies were first performed on lighter alkanes such as ethane and propane. It has been 
demonstrated that both ethane and propane undergo catalytic partial oxidation over rhodium catalysts at a fuel conversion greater than $80 \%$, and they produce synthesis gas components at selectivities higher than $90 \%$ [44]. Huff et al. have shown that $n$-butane can also be converted into synthesis gas through catalytic partial oxidation over a rhodium catalyst [45]. Also, there is an interest in the development of a portable reactor to convert fuels such as gasoline and diesel into synthesis gas for fuel cell applications since those fuels have an existing distribution infrastructure [21]. This gave way to a series of studies on the catalytic partial oxidation of higher hydrocarbons such as $\mathrm{n}$-hexane, isooctane, $\mathrm{n}$ decane, and hexadecane. O'Connor et al. demonstrated that the catalytic partial oxidation of $n$-hexane and isooctane over rhodium catalysts successfully produced syngas at yields over $90 \%$ and fuel conversions exceeding $95 \%$ [24]. Furthermore, n-decane and hexadecane exhibited fuel conversions over $99 \%$ when used for the production of syngas through catalytic partial oxidation over rhodium catalysts. The hydrogen and carbon monoxide selectivities were above $80 \%[23]$.

The research was further extended to fuels such as low sulfur diesel. In the same publication as the $n$-decane and hexadecane findings, Krummenacher et al. have given evidence that low sulfur diesel fuel can achieve $98 \%$ conversion through catalytic partial oxidation to produce mostly hydrogen and carbon monoxide [23]. 


\section{Catalytic Partial Oxidation of Alcohols}

As discussed earlier, it is desired to design an efficient and portable syngas production unit for fuel cell-powered applications such as automobiles. In order to do this, it is necessary that the fuel used to produce the synthesis gas be easily transported and stored. Other than gasoline and diesel, alcohols qualify as relatively inexpensive, easily transported and stored fuels.

Methanol is an inexpensive fuel, which is easily produced from natural gas or petroleum. Also, it has the highest atomic ratio of hydrogen to carbon among liquid hydrocarbon fuels, since it has four hydrogen atoms for a single carbon atom. Its catalytic partial oxidation reaction was first observed by Huang and Wang, over copper-zinc catalysts. They had reported that the methanol conversion increased when oxygen was added to the methanol steam reformer's feed. [46]. The addition of alumina to the copper-zinc catalyst for the methanol partial oxidation reaction was then studied by Alejo et al. They found that the presence of aluminum in the catalyst caused a decrease in the hydrogen and carbon dioxide selectivities [47]. Cubeiro and Fierro then investigated the catalytic activity of palladium supported on zinc oxide and on zirconia for the partial oxidation of methanol. They observed high methanol conversions for both catalysts. However, the use of palladium supported on zirconia resulted in better hydrogen and carbon monoxide yields. They noticed that the reaction of methanol over the palladium supported on zinc oxide followed a two-step 
process, as it was the case for methane. The methanol underwent deep oxidation followed by reforming reactions and the product stream contained mostly hydrogen and carbon dioxide [48]. Traxel and Hohn were the first to research the catalytic partial oxidation of methanol over rhodium- and platinum-coated alumina monoliths. Platinum and rhodium both gave similar reaction temperatures and methanol conversions. The platinum catalyst yielded higher carbon monoxide selectivity than the rhodium catalyst, although its methane selectivity was slightly higher. Their experimental data indicated that the hydrogen selectivities for both catalysts were similar at low methanol to oxygen feed ratios and that at higher ratios, platinum gave greater hydrogen selectivities [9].

The most considerable drawback of methanol is its production's dependence on fossil fuels. Since it is produced from petroleum or natural gas, it does not constitute a renewable fuel. Research over the last few years has looked into the possible use of bio-fuels to produce syngas components. One of the most mentioned bio-fuels in question is bio-ethanol. It is easily stored and handled, and produced renewably from biomass sources. Its use as a fuel would give way to a close carbon cycle, since the carbon dioxide formed from its consumption will be expended in the growth of the biomass used to produce the ethanol. Salge et al. have reported that the partial oxidation of ethanol over rhodium-ceria supported on alumina yields greater synthesis gas selectivities than similar rhodium, rhodium-ruthenium, platinum, and palladium catalysts. The maximum hydrogen 
selectivity observed with the rhodium-ceria catalyst was $80 \%$ [31]. In order to study the effect of the size and structure of the alcohol used, Wanat et al. observed the partial oxidation of 1-propanol and 2-propanol. It was found that the two alcohols produced large byproducts at a greater extent than methanol and ethanol [30].

\section{Catalytic Partial Oxidation of Biodiesel}

As the research has begun its focus on the use of renewable fuels, biodiesel became a fuel of interest. Most of the biodiesel is produced by reacting vegetable oil or used cooking oils with methanol. However, it is also possible to obtain biodiesel from the reaction of animal fats with methanol. Given the nature of the vegetable oils and/or animal fats used to produce the biodiesel, the latter is a mixture of methyl esters [11]. Subramanian and Schmidt examined the catalytic partial oxidation of soybean oil-derived biodiesel over rhodium-ceria catalysts supported on alumina foam monoliths. Although their research paper targeted the production of olefins from the reaction, they gave details about the production of hydrogen and carbon monoxide from biodiesel. The hydrogen selectivity was as high as $85 \%$ and the carbon monoxide selectivity reached $80 \%$ at the lower feed ratios while the fuel conversion was found to be above $90 \%$. The findings suggest that synthesis gas components can be produced in satisfactory yields from biodiesel. It is possible to tune the catalytic partial oxidation reactor to optimize the syngas components' selectivities and the biodiesel conversion [34]. 


\section{Materials and Methods}

\section{Catalyst Preparation}

The support material used for the catalytic metal is a cylindrical foam monolith (Vesuvius Hi-Tech) with a diameter of $17 \mathrm{~mm}$, length of $10 \mathrm{~mm}$, pore density of 80 pores per inch, and porosity of 0.83 . The approximate monolith composition is 92\% $\alpha$-alumina and $8 \%$ silica. The monoliths are first washcoated so as to increase the surface area and decrease the pore diameter. The washcoat consists of a slurry prepared from fumed $\gamma$-alumina (Degussa) and distilled water. The blank monolith is weighed and the weight of $\gamma$-alumina corresponds to $5 \%$ of the monolith's weight. Once the required amount of alumina is weighed out on a small weighing dish, it is mixed with just enough distilled water so that a homogeneous slurry is obtained. The alumina slurry is then pipeted onto the monolith. If the monolith reached its saturation before all the slurry is used up, it is allowed to dry overnight before the remainder of the slurry is deposited. The monolith is dried for at least 12 hours before it is weighed again to determined the washcoated monolith's weight and the actual washcoat loading. The average washcoat loading for all monoliths used in this work was about $5.1 \mathrm{wt} \%$.

For the preparation of a catalyst containing a single metal, the aimed catalyst loading is $5.0 \mathrm{wt} \%$. However, a bimetallic catalyst will imply a mixture of the two 
catalytic metals, corresponding to a target loading of $2.5 \mathrm{wt} \%$ for each metal. All loadings are calculated on the basis of the washcoated monolith's weight .The catalytic metal is first deposited onto the washcoated monolith as an aqueous solution of a precursor salt. The precursor salts are the following: rhodium (III) nitrate solution (Alfa Aesar), cerium (III) nitrate hexahydrate (Acros Organics), hydrogen hexachloroplatinate (IV) (Sigma Aldrich), cupric nitrate trihydrate (Fisher), and palladium (II) nitrate solution (Sigma Aldrich). The precursor salt(s) is(are) weighed out on a small weighing dish. A minimal amount of distilled water is then added to the weighing dish so that there is just enough to dissolve all the salts. This corresponds to about 1-2 $\mathrm{ml}$ of distilled water. As for the washcoat slurry, the salt solution is pipeted onto the washcoated monolith until the monolith is saturated with liquid. The monolith is then partially covered and allowed to dry overnight before the addition of the remainder of the salt solution. The monolith is then left to dry overnight once more and it is then calcined at $600^{\circ} \mathrm{C}$ for 8 hours. The finished catalyst is weighed one last time and an actual loading is calculated. Although the target loadings calculated are taken as the weight percent loading of the metal, the final catalyst does not consist of pure metals on the surface of the alumina support but in fact of metal oxides. Hence the actual loading, which is calculated from the final weight of the monolith, is the weight percent loading of metal oxides and is therefore slightly greater than the metal loading used to determine the required amount of precursor salts. 


\section{Reactor Setup}

A diagram of the reactor setup is shown in Figure 1 shown below. The methyl acetate $(99 \%$, Sigma Aldrich) is stored in a fuel tank located near the reactor. The tank is pressurized with nitrogen gas (BOC) to a pressure of 3 psig (122 $\mathrm{kPa})$. A $316 \mathrm{~L}$ stainless steel, $1 / 4$ inch-diameter pipe $(0.635 \mathrm{~cm}$, Swagelok) connects the fuel tank to the fuel injector. The fuel injector feeds the methyl acetate in small intermittent jets into the top part of the reactor. At a short distance below, extradry air (BOC) is supplied through a reactor sidearm. The flow of air is managed by a Brooks Smart Series 5850 S mass flow controller (Emerson) hooked onto an air cylinder. The upper part of the reactor is heated with the use of heating tape wrapped around its outer wall. The heating tape's power output was controlled by a variable transformer. The heating tape setting is such that the outer reactor wall temperature is about $100^{\circ} \mathrm{C} \pm 40^{\circ} \mathrm{C}$ in order to ensure that the temperature inside the reactor at that section is above the normal boiling point of methyl acetate, which is $57^{\circ} \mathrm{C}$. To achieve these temperatures with the various flow rates and feed ratios used in the experiments, the variac was varied between $20 \%$ and $45 \%$ of the $140 \mathrm{~V}$ input voltage. The outer reactor wall temperature was monitored by the use of a K-type thermocouple (Omega) introduced between the outer reactor wall and the heating tape. In that section of the reactor, two blank monoliths are wrapped in Fiberfrax aluminosilicate paper (Unifrax) and inserted in the reactor. The two blanks are about 15 centimeters upstream of the catalyst setup and act as mixing blanks; they help to vaporize the methyl acetate upon contact. Tthe 
methyl acetate and air mixture reacts as it passes through the catalyst setup further downstream in the reactor. The catalyst-supporting monolith is placed between two blank monoliths, which serve as axial heat shields. All three monoliths are wrapped in a Fiberfrax aluminosilicate paper to prevent reactant bypass. A small hole is made right through the center of the downstream blank monolith and a K-type thermocouple is inserted in the aperture in order to measure and record the catalyst's back face temperature. The product gases are sampled with a gas tight, luer lock syringe (Agilent) for analysis in a dual-column gas chromatograph (Agilent). The product gas stream is vented through a reactor sidearm downstream from the catalyst setup.

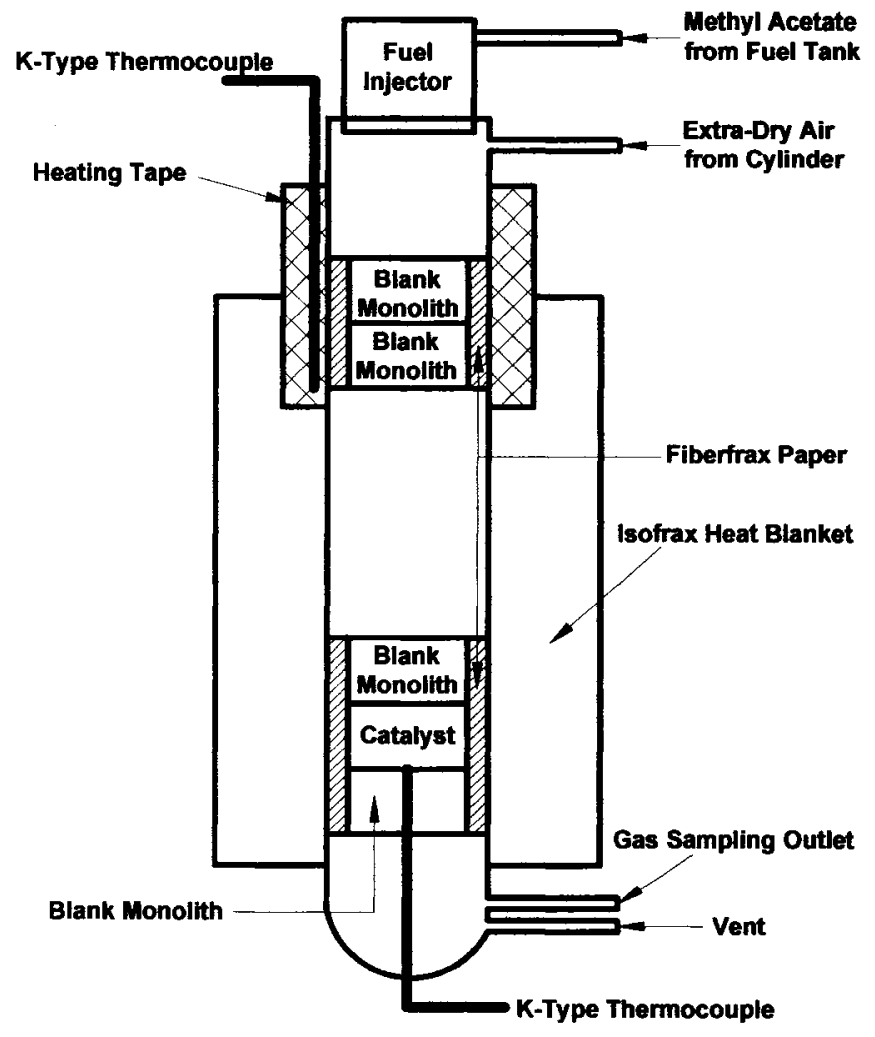

Figure 1: A diagram of the reactor setup 


\section{Reactor Ignition}

In order to ignite the catalyst in a minimal amount of time, the heating tape around the upper section of the reactor is switched on to the desired setting. When the thermocouple positioned under the heating tape indicates an outer reactor wall temperature of at least $70^{\circ} \mathrm{C}$, a Bunsen burner flame is lit and directed onto the catalyst. The catalyst is allowed to heat up to about $200^{\circ} \mathrm{C}$, at which point the air and methyl acetate are fed to the reactor in the desired feed stoichiometry. Catalyst light-off occurs when the back face temperature significantly increases at a greater rate. The Bunsen burner flame is then extinguished and removed. The reactor is consequently wrapped in a heat blanket consisting of a layer of Isofrax insulation (Unifrax) surrounded by heavy duty aluminum foil (Alcan) before it is left to reach steady state operation.

\section{Data Acquisition and Process Control}

\section{Electric Circuit Setup}

The two K-type thermocouples, the fuel injector and the mass flow controller are managed with the use of the LabVIEW 7.1 software (National Instruments). The use of these instruments is managed by a National Instruments Compact FieldPoint programmable automation controller with an eight-channel thermocouple input module, an eight-channel 16-bit analog input module, an 
eight-channel $10 \mathrm{~V}$ analog voltage output module, and corresponding connector blocks. The controller is connected directly to a computer with an Ethernet crossover cable.

A separate custom-made circuit box was made to complete the data acquisition and process control setup. The circuit included two monolithic thermocouple amplifiers with cold junction compensation (Analog Devices), a unity gain operational amplifer (Analog Devices) , a power transistor, a $60 \mathrm{~W}$ power supply (Omron Electronics), and a $90 \mathrm{~W}$ power supply (G-Power Co). The monolithic thermocouple amplifier handles the cold junction compensation and linearizes the thermocouple response. Since the Compact FieldPoint controller's power output is insufficient to supply for all applications, the thermocouple amplifiers are connected to the $60 \mathrm{~W}$ power supply to compensate for the lack of power. The unity gain operational amplifier acts as a buffer for the voltage sent from the computer to the mass flow controller. For the same reason as explained for the thermocouple amplifiers, the unity gain operational amplifier is also wired to the $60 \mathrm{~W}$ power supply. The fuel injector is connected to a power transistor, which functions as a switch. The transistor is connected to the $90 \mathrm{~W}$ power supply in order to supply the power output needed for the fuel injector operation. 


\section{Process Control Program Development}

A single virtual instrument (.vi) file has been created to control and monitor all the applications. Given the reactor setup, it is essential for the program to allow independent contol of each application. The two thermocouples are programmed in such a way that they will monitor and display the temperatures while the virtual instrument file is running. In contrast, the mass flow controller and the fuel injector have separate switches on the program's interface, to allow for the methyl acetate and air feeds to be activated independently from each other. The mass flow controller's subroutine is designed to convert a user-inputted flow rate into the corresponding voltage analog signal to be sent to the mass flow controller. In contrast, the fuel injector subroutine is more complex. Since the fuel injector can only be either open or closed, a pulse signal is necessary to operate it for various flow rates. Furthermore, the use of the Compact FieldPoint controller restrains the use of LabVIEW's built-in pulse generation subroutine. Hence a pulse signal was simulated by using a flat sequence structure, which consists of a series of subdiagrams for the program to execute sequentially. In this program, the structure has only two frames, therefore two series of commands to perform in series. One frame contains the subroutine needed to open the fuel injector for a user-defined amount of time (i.e. the on time) while the other frame commands the fuel injector to shut off for another user-defined amount of time (i.e. the off time). Both times must be entered in milliseconds, before the fuel injector subroutine's switch is activated. As the fuel injector is running, the pulse signal's period, frequency, and duty cycle are calculated and displayed on the 
interface. All the subroutines are included in a continuous loop in order to ensure that all the input and output values are continuously refreshed.

For better tracking of the reactor parameters, an additional subroutine was added to the loop for data logging. The thermocouples' readings, the air flow rate, and the fuel injector's duty cycle and frequency were logged into a LabVIEW measurement (.Ivm) file. The logging process was regulated by the use of a switch such that the switch must be pressed for the data to be instantaneously logged for that exact moment only.

\section{Instrument Calibrations}

The mass flow controller was calibrated for voltages between $1.15 \mathrm{~V}$ and $3 \mathrm{~V}$, which correspond to air flow rates ranging between 0.5 and 8.93 standard liters per minute (slpm). This was done with the use of a microprocessor-controlled flow calibrator (Gillian) connected to the mass flow controller's output tube. A known voltage is sent to the mass flow controller, and the corresponding flow rate is recorded by the flow calibrator. Several data points can be collected by the flow calibrator, which can then calculate the average flow rate. Hence 10 readings have been done for each voltage settings and the data was then plotted against the voltage applied. A linear regression is fit to the data and the resulting regression line formula constitutes the calibration curve for the mass flow 
controller. Moreover, the fuel injector was also calibrated for a fuel tank pressure of 3 psig $(122 \mathrm{kPa})$, and a pulse signal frequency of $4 \mathrm{~Hz}$. The calibration was performed with an Erlenmeyer flask, a stopwatch, and an analytical balance. The empty and bone-dry flask's weight is recorded prior to the calibration and the flask is then placed underneath the fuel injector's output. On and off times for the fuel injector are then inputted into the program and the subroutine is switched on for a certain amount of time, which is monitored with the stopwatch. Once the subroutine is stopped, the run time is recorded and the flask is weighed. The difference in the weight of the flask is the mass of the methyl acetate given out by the fuel injector within the run time. The average fuel injector's flow rate is then calculated by dividing the mass of methyl acetate over the run time. This is done at least three times for every set of on and off times (i.e. every duty cycle) and the average of the flow rates is determined. The duty cycle is calculated by dividing the on time over the total period of the signal. The flow rates are plotted against the fuel injector's duty cycles to yield the fuel injector's calibration curve.

\section{Gas Chromatography}

\section{Gas Chromatograph Setup}

In order to determine the product stream composition, product gas samples were injected in a dual-column gas chromatograph (GC). Helium (BOC) is the carrier gas used in the GC. Since the product gases are a mixture of permanent gases 
(nitrogen $\left(\mathrm{N}_{2}\right)$, oxygen $\left(\mathrm{O}_{2}\right)$, carbon monoxide $(\mathrm{CO})$, carbon dioxide $\left(\mathrm{CO}_{2}\right)$, hydrogen $\left(\mathrm{H}_{2}\right)$, methane $\left(\mathrm{CH}_{4}\right)$ ), water $\left(\mathrm{H}_{2} \mathrm{O}\right)$, hydrocarbons (ethane, ethylene, acetylene, propane, propylene, propyne, n-butane), and various oxygenates (methanol, ethanol, acetaldehyde, methyl acetate), it was necessary to use two columns to separate the various components. For this purpose, the GC was equipped with a PLOT Q column to separate the water, carbon dioxide, alkanes, and oxygenates, and a Molesieve column to separate the remainder of the permanent gases. The PLOT Q column is a bonded polystyrene-divinylbenzene column, and the first column through which the gas sample will flow. All the permanent gases will exit the column first, with the last one being $\mathrm{CO}_{2}$. An airactuated six-port valve controls the direction of the gas flow. Depending on the valve's setting, the gas sample's constituents may or may not flow through the Molesieve column once it has exited the PLOT Q column. The components' relative amounts are determined from the signal output from a thermal conductivity detector (TCD). The TCD allows for the detection of all the components in the gas sample, since it responds to the differences in thermal conductivities of the components from that of the carrier gas [49].

\section{Method Development and Optimization}

A gas chromatography method is developed for the analysis of the product gases, based on the method previously used for the analysis of the product gases from the catalytic partial oxidation of $\mathrm{CH}_{4}[5,43]$. The previous method 
uses two programmed valve switches and temperature ramping, which allow for the separation and detection of all the gaseous products. It was first important to determine the required analysis time, which allowed for separation of all of the components in the gas sample. Since certain compounds such as $\mathrm{CO}_{2}$ and methyl acetate will remain absorbed in the Molesieve column if allowed to pass through to it, the analysis time is found by injecting a gas sample into the GC with the valve at the "on" position for the gas to bypass the Molesieve column. Also, a temperature ramping needs to be programmed because of the compounds' different boiling points. The GC is then programmed to gradually increase its oven temperature from $50^{\circ} \mathrm{C}$ up to $195^{\circ} \mathrm{C}$. The last gas product to exit the column is the methyl acetate. The temperature programming was adjusted so that all the components' GC signal peaks are distinct from each other. The analysis time is then the amount of time until the methyl acetate has gone through the TCD.

It is known that the permanent gases are the first compounds to exit the PLOT Q column and all of them with the exception of $\mathrm{CO}_{2}$ are then detected as a single peak. In contrast, the carbon dioxide will absorb permanently to the HP Molesieve column if it passes to the latter. In order to avoid such problems, it is necessary to program a valve switch to isolate all of the permanent gases with the exception of $\mathrm{CO}_{2}$ in the Molesieve column while the remainder of the gas sample constituents will exit the PLOT Q column and pass through the TCD. The method starts with the valve switched off to allow the permanent gases into the 
Molesieve column. Therefore, the valve must be switched on right before the $\mathrm{CO}_{2}$ exits the PLOT Q column. This is done by observing the retention time of the first peak observed from the gas analysis done for the optimization of the analysis time. That peak corresponds to the $\mathrm{O}_{2}, \mathrm{~N}_{2}, \mathrm{CO}, \mathrm{H}_{2}$, and $\mathrm{CH}_{4}$. The valve switch must be placed immediately after that first peak. With the first valve switch, the $\mathrm{H}_{2}, \mathrm{O}_{2}, \mathrm{~N}_{2}, \mathrm{CH}_{4}$, and $\mathrm{CO}$ are essentially trapped in the Molesieve column while the remainder of the gas sample is allowed to exit the PLOT $Q$ column and proceed to the TCD. No carrier gas is allowed through the Molesieve column during that time and hence the compounds trapped in it cannot exit until the gas flow is restored to the column. Hence it is necessary to switch off the valve so as to elute the gases trapped in the Molesieve column. Since the temperature ramping is not modified while the valve switches are set, the retention times do not change for the $\mathrm{CO}_{2}, \mathrm{H}_{2} \mathrm{O}$, hydrocarbons, and oxygenates. The second valve is therefore timed about 1-2 minutes after the last peak that appears on the previous GC signal and that corresponds to the methyl acetate. It was then noticed after a GC run that the oxygen and nitrogen peaks appear unresolved as a result of the permanent gases exiting the Molesieve column at a high temperature. This prompts for a modification of the temperature programming. Once the methyl acetate's retention time has passed, the GC is programmed to start a gradual cooling phase, reaching a final temperature of $50^{\circ} \mathrm{C}$. This way, the GC is allowed to cool slightly before the second valve switch occurs and the permanent gases' peaks come out distinctly within 5 minutes after the second valve switch. 


\section{Gas Chromatograph Calibrations}

Prior to experimentation, it is crucial that the GC be calibrated for all the compounds to be measured. The relative peak areas corresponding to the compounds are related to their amounts present in the sample. For this purpose, response factors must be calculated for the components present in the gas sample. A response factor is an calibration factor by which a measured peak area is multiplied in order to obtain a corrected area directly related to the amount of compound present in the injected gas sample. Hence a response factor is needed for each component present in the gas sample. Nitrogen was chosen as a reference and assigned a response factor of exactly 1.00 since it is present in large quantities in the gas sample and it is an inert. In order to obtain the response factors, calibration standards are required for a single-point calibration. These are mixtures of known amounts of compounds in nitrogen. Multiple GC injections were done to verify the precision of the single-point calibration. Three commercially available calibration gas standard canisters (Matheson Tri-Gas) were used to calibrate for $\mathrm{O}_{2}, \mathrm{~N}_{2}, \mathrm{CO}, \mathrm{H}_{2}, \mathrm{CH}_{4}$, ethane, ethylene, acetylene, propane, propylene, n-butane, and n-hexane with respect to nitrogen. The response factors for these components are calculated with the following equation:

$$
R F_{i}=\frac{A_{N_{2}}}{A_{i}} \cdot \frac{y_{i}}{y_{N_{2}}}
$$

where $R F_{i}$ represents the response factor for component $i, A_{N 2}$ stands for the measured nitrogen peak area, $A_{i}$ denotes the measured peak area for 
component $\mathrm{i}, \mathrm{y}_{\mathrm{N} 2}$ is the mole fraction of nitrogen in the calibration standard used, and $y_{i}$ designates the mole fraction of component $i$ in the calibration standard used. The remainder of the compounds were calibrated with the preparation and use of a liquid calibration standard. Known amounts of methanol, ethanol, and methyl acetate were dissolved in n-hexane and a small volume of the mixture is injected to the GC for every run. As the components are here diluted in n-hexane, their response factors are related to nitrogen through the response factor of $n$ hexane with respect to nitrogen. Hence the response factors of methanol, ethanol, and methyl acetate are determined by

$$
R F_{i}=\frac{A_{n-\text { Hexane }}}{A_{i}} \cdot \frac{y_{i}}{y_{n-\text { Hexane }}} \cdot R F_{n-\text { Hexame }}
$$

where $A_{n-H e x a n e,} y_{n-H e x a n e}$, and $R F_{n-h e x a n e}$ denote the measured peak area, mole fraction, and response factor (with respect to nitrogen) of $n$-hexane. Due to the high reactivity of acetaldehyde with alcohols and esters, the acetaldehyde is diluted in $\mathrm{n}$-hexane as a separate calibration standard. Its response factor is determined in the same manner as the methanol, ethanol, and methyl acetate.

\section{FactSage}

An equilibrium product composition for the various $\mathrm{C} / \mathrm{O}$ feed ratios and gas hourly space velocities used in the experiments was calculated from the FactSage thermochemical software and databases (CRCT-ThermFact, GTT-Technologies). 
The Equilib module was used to determine the equilibrium product composition for every set of reactor conditions through the Gibbs energy minimization method. The use of the FactSage software has certain limitations. For instance, it is impossible to enter the reactants' molar flow rates directly into the software for computations. As a result of this limitation, the reactor's feed was entered into FactSage in number of moles of reactants on the basis of one minute of gas flow. A total pressure of 1 atmosphere was used. Also, the temperature of the system was taken to be the back face temperature corresponding to the catalyst, feed ratio, and gas hourly space velocity of interest.

\section{Reactor Parameters and Performance Criteria}

\section{Reactor Parameters}

The effects of the gas hourly space velocity and the $\mathrm{C} / \mathrm{O}$ feed ratio on the reactor temperature and the product composition are studied in this work. These were selected as the independent variables since previous research on the partial oxidation of alkanes has shown that the catalytic metal loading and the catalyst's support material have lesser effects on the conversions and selectivities than the gas hourly space velocity and feed stoichiometry, regardless of the fuel or catalyst used [25]. 
The gas hourly space velocity (GHSV) is given as the gas flow rate at standard conditions $\left(0^{\circ} \mathrm{C}, 1 \mathrm{~atm}\right)$ divided by the reactor volume. Since the volume of the reactor is in fact the void volume of the catalyst through which the gas flows, the GHSV is calculated as:

$G H S V=\frac{Q_{\text {total }, S T P}}{\varepsilon V_{\text {monolith }}}$

where $Q_{\text {total,STP }}$ is the total volumetric flow rate entering the reactor at standard temperature and pressure, $\varepsilon$ is the monolith void fraction, and $V_{\text {monolith }}$ is the volume of the monolith.

The $\mathrm{C} / \mathrm{O}$ feed ratio is defined as the number of carbon atoms entering the reactor divided by the number of oxygen atoms entering the reactor. Therefore pure methyl acetate has a $\mathrm{C} / \mathrm{O}$ ratio of 1.5 while syngas has a $\mathrm{C} / \mathrm{O}$ ratio of 1.0 . It is important to note that the overall partial oxidation of methyl acetate (8) is in fact an endothermic reaction, as it was reported to be the case for ethanol [8].

$\mathrm{C}_{3} \mathrm{H}_{6} \mathrm{O}_{2}+1 / 2 \mathrm{O}_{2} \rightarrow 3 \mathrm{CO}+3 \mathrm{H}_{2} \quad \Delta \mathrm{H}=+78.4 \mathrm{~kJ} \cdot \mathrm{mol}^{-1}$

This requires the input of a small amount of excess oxygen in order to have some combustion (9) occurring in the reactor, thus supplying the heat for sustaining the autothermal operation of the reactor.

$\mathrm{C}_{3} \mathrm{H}_{6} \mathrm{O}_{2}+31 / 2 \mathrm{O}_{2} \rightarrow 3 \mathrm{CO}_{2}+3 \mathrm{H}_{2} \mathrm{O} \quad \Delta \mathrm{H}=-1496 \mathrm{~kJ} \cdot \mathrm{mol}^{-1}$ 


\section{Reactor Performance Criteria}

The catalyst's suitability for the CPO of methyl acetate was evaluated on the basis of the resulting reactant conversions and the product selectivities. The conversion of a reactant $i$ is defined as the ratio of the amount of reactant $i$ which was consumed in the reactor, over that which was fed to the reactor:

$$
X_{i}=\frac{F_{i, \text { in }}-F_{i, \text { out }}}{F_{i, \text { in }}}
$$

where $F_{i, i n}$ is the molar flow rate of reactant $i$ entering the reactor and $F_{i, o u t}$ is the molar flow rate of reactant $i$ exiting the reactor.

The selectivity of element $i$ to form product $j\left(S_{i, j}\right)$ is calculated by:

$$
S_{i, j}=\frac{v_{i, j} F_{j, \text { out }}}{\sum_{k} v_{i, k} F_{k, \text { out }}}
$$

where $v_{i, j}$ is the stoichiometric number of atoms of element $i$ in product $j$. The denominator is the summation over all species, $k$. In this work, the selectivities for hydrogen, water, carbon monoxide, and carbon dioxide are shown, since they are the major reactor products. Since the hydrogen and water selectivities are both calculated on the basis of atomic hydrogen and the carbon dioxide and carbon monoxide selectivities are based on atomic carbon, the $i$ subscript in the selectivity variable is omitted. The selectivities pertaining to a single element 
(carbon or hydrogen) presented in this work may not add up to $100 \%$, since not all of the products are shown. 


\section{Results}

As the experiments were performed, it was observed that only the rhodium (Rh) and rhodium-ceria $(\mathrm{RhCe})$ catalysts gave a stable, steady-state reactor operation. Out of the two, only the Rh catalyst showed signs of carbon formation on the downstream heat shield and on the reactor walls. The platinum (Pt) catalyst never attained light-off or steady state operation. This agrees with observations made in two publications about the CPO of alcohols $[30,31]$. On the other hand, the palladium $(\mathrm{Pd})$ catalyst would light off. However the extensive coke formation observed on the catalyst caused its deactivation within 30 to 40 minutes. Also, the copper $(\mathrm{Cu})$ catalyst behaved similarly to the Pt catalyst and also showed signs of changes in oxidation states. The change in oxidation states is easily observed through the change of colour of the catalyst. As a result of the catalyst's calcination in air, the Cu catalyst's initial composition is mostly copper (II) oxide (CuO), which coloration is black and corresponds to Cu's highest oxidation state. When the $\mathrm{Cu}$ catalyst would light off, the reactions depleted the oxygen from the feed and reduced the $\mathrm{CuO}$ to copper $(\mathrm{I})$ oxide $\left(\mathrm{Cu}_{2} \mathrm{O}\right)$, which has a reddish color. This transition in oxidation states is supported by findings from a previous study [50]. The second oxidation state may not be catalytically active for the CPO of methyl acetate, which would explain the $\mathrm{Cu}$ catalyst's failure to reach steady state operation. Furthermore, the Cu catalyst showed signs of catalyst migration, as some copper oxide was found on the downstream heat shield after the reactor is shut down and disassembled. Since $\mathrm{Pt}, \mathrm{Cu}$, and $\mathrm{Pd}$ are now found to be 
unsuitable catalysts for the CPO of methyl acetate, the results shown in the remainder of this section will be those of the $\mathrm{Rh}$ and $\mathrm{RhCe}$ catalysts.

\section{Feed Stoichiometry}

Although experiments were performed at several GHSVs, the graphs used to discuss the differences between $\mathrm{Rh}$ and $\mathrm{RhCe}$ and the effects of feed stoichiometry on the reactor performance are shown at a GHSV of $143300 \mathrm{~h}^{-1}$. For all of the graphs, the solid circle $(\bullet)$ symbol represents the experimental results for the Rh catalyst while the hollow circle (o) denotes the experimental results for the $\mathrm{RhCe}$ catalyst. The stoichiometric $\mathrm{C} / \mathrm{O}$ ratio for the $\mathrm{CPO}$ of methyl acetate is 1 while that for the combustion of methyl acetate is $1 / 3$. As it was mentioned before, the CPO of methyl acetate is an endothermic process and it is necessary to provide some excess oxygen for some combustion of methyl acetate to occur and supply the heat necessary for the CPO. Consequently, the reactor is operated at $\mathrm{C} / \mathrm{O}$ ratios lower than 1 , ranging between 0.75 and 0.87 .

Figure 2 illustrates the effect of varying $\mathrm{C} / \mathrm{O}$ feed ratios on the catalyst's back face temperature. Overall, the back face temperature for both catalysts decreases continuouly as the $\mathrm{C} / \mathrm{O}$ ratio increases. At the lower $\mathrm{C} / \mathrm{O}$ ratio, the RhCe catalyst exhibits back face temperatures more than $200^{\circ} \mathrm{C}$ greater than 
those of the $\mathrm{Rh}$ catalyst. The $\mathrm{RhCe}$ catalyst showed back face temperatures between $969^{\circ} \mathrm{C}$ and $790^{\circ} \mathrm{C}$.

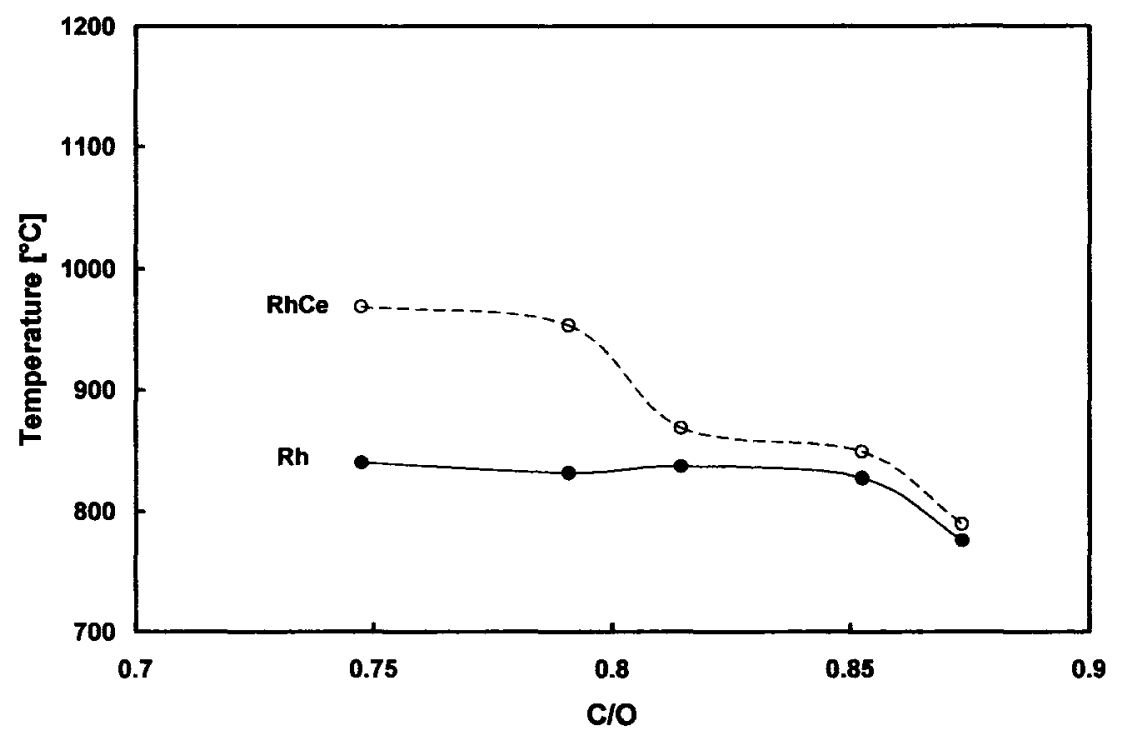

Figure 2: Response of the back face temperature of the $\mathrm{Rh}$ and $\mathrm{RhCe}$ catalysts

Since all experiments were performed in fuel-rich conditions, it was expected that the oxygen conversion would be very close to $100 \%$. According to Figure 3 , the resulting oxygen conversions remain relatively constant above $95 \%$ for both catalysts and for all operating conditions. There seems to be no difference in oxygen conversion between the catalysts.

Both catalysts demonstrate very similar methyl acetate conversions (Figure 4) over most of the range of the feed ratios studied, despite the higher methyl 
acetate conversion shown by the $\mathrm{Rh}$ catalyst at the lower $\mathrm{C} / \mathrm{O}$ ratio. Generally, the methyl acetate conversion of both catalysts decreases continuously with response to increases in $\mathrm{C} / \mathrm{O}$ ratios. The Rh catalyst's methyl acetate conversion dropped from $92 \%$ to $56 \%$ and the RhCe catalyst's methyl acetate conversion declined from $79 \%$ to $53 \%$ as the $\mathrm{C} / \mathrm{O}$ feed ratio increased from 0.75 to 0.87 .

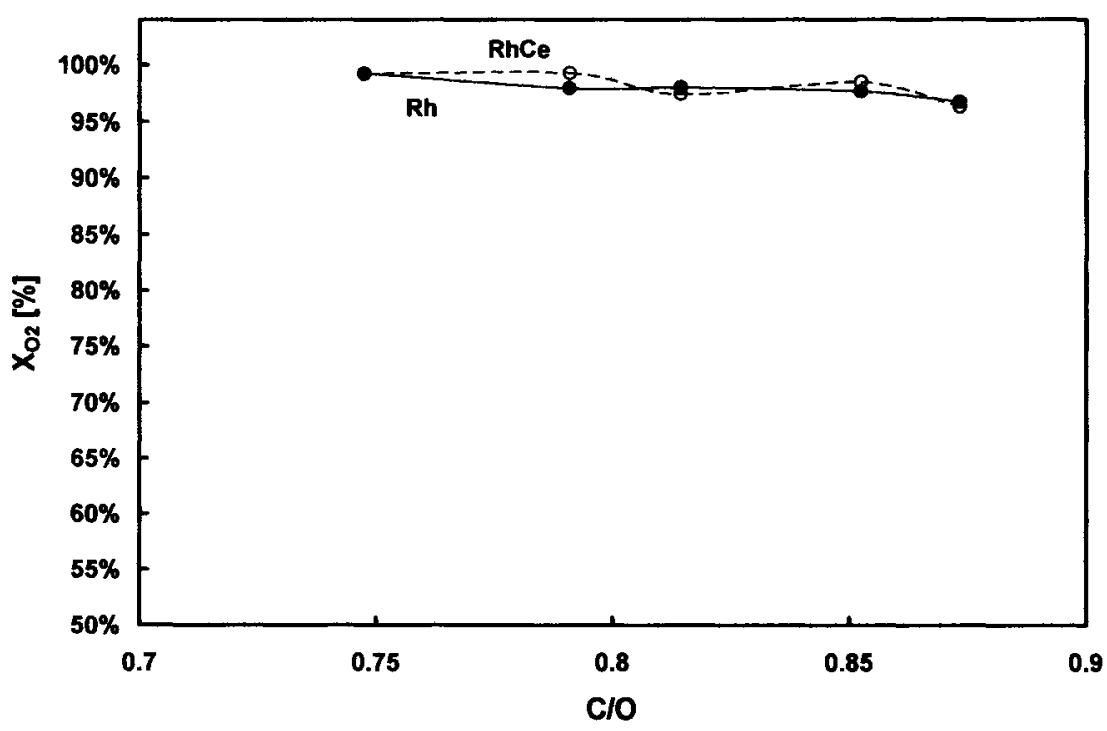

Figure 3: Response of the oxygen conversion $\left(\mathrm{X}_{\mathrm{O} 2}\right)$ of the $\mathrm{Rh}$ and $\mathrm{RhCe}$ catalysts with respect to the $\mathrm{C} / \mathrm{O}$ ratio

While the $\mathrm{C} / \mathrm{O}$ feed ratio increased, a decrease in hydrogen selectivity (Figure 5) was observed for both catalysts. In general, the RhCe catalyst yielded greater hydrogen selectivities than the Rh catalyst. The Rh catalyst's hydrogen selectivity dropped from $32 \%$ to $12 \%$ over the range of $\mathrm{C} / \mathrm{O}$ feed ratios whereas the $\mathrm{RhCe}$ catalyst experienced a reduction in hydrogen selectivity from $36 \%$ to $16 \%$. On the other hand, the water selectivities (Figure 6) augmented with every increase in 
$\mathrm{C} / \mathrm{O}$ feed ratio. The Rh catalyst's water selectivity rose from $27 \%$ to $46 \%$ whereas the RhCe catalyst's water selectivity increased from $40 \%$ to $55 \%$. Once more, the RhCe catalyst appears to yield more water than the Rh catalyst over the range of C/O ratios studied.

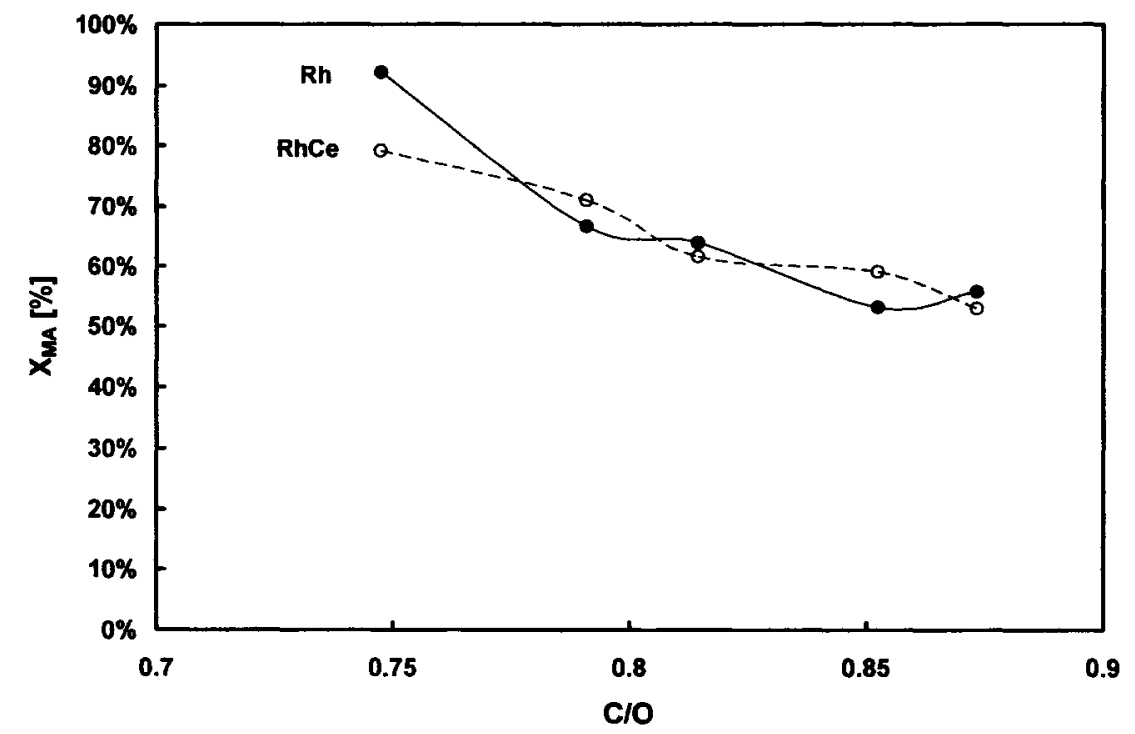

Figure 4: Response of the methyl acetate conversion $\left(X_{M A}\right)$ of the Rh and RhCe catalysts with respect to the $\mathrm{C} / \mathrm{O}$ feed ratio 


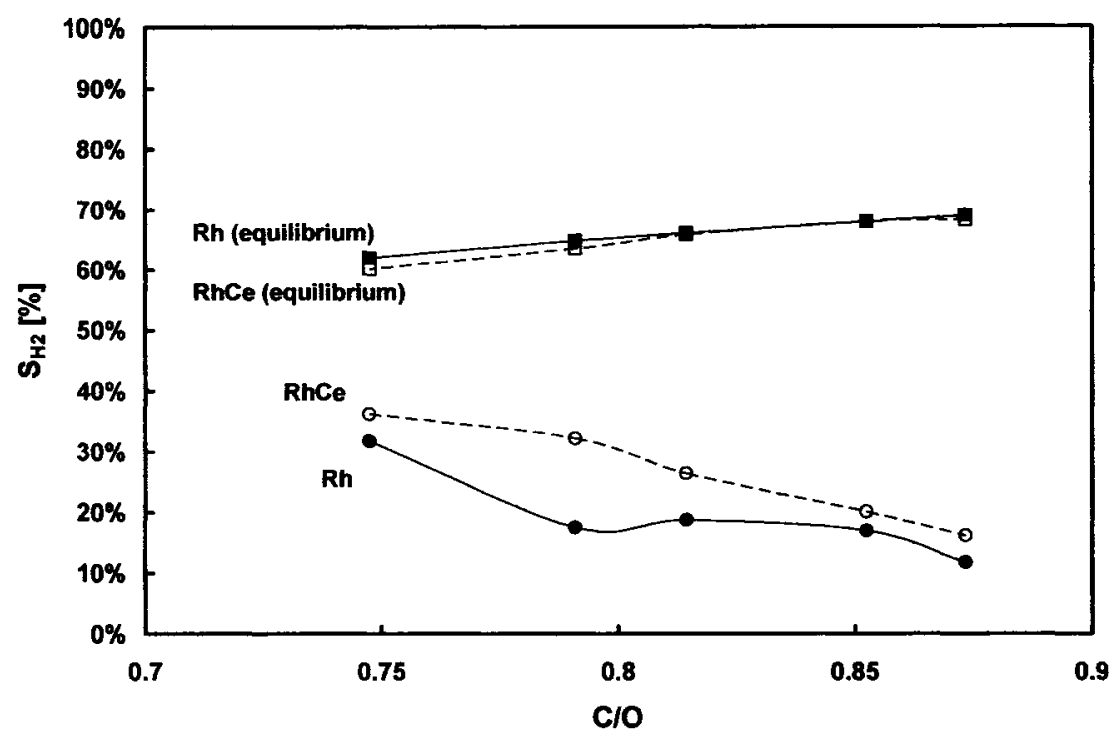

Figure 5: Response of the hydrogen selectivity $\left(\mathrm{S}_{\mathrm{H} 2}\right)$ of the $\mathrm{Rh}$ and $\mathrm{RhCe}$ catalysts with respect to the $\mathrm{C} / \mathrm{O}$ feed ratio

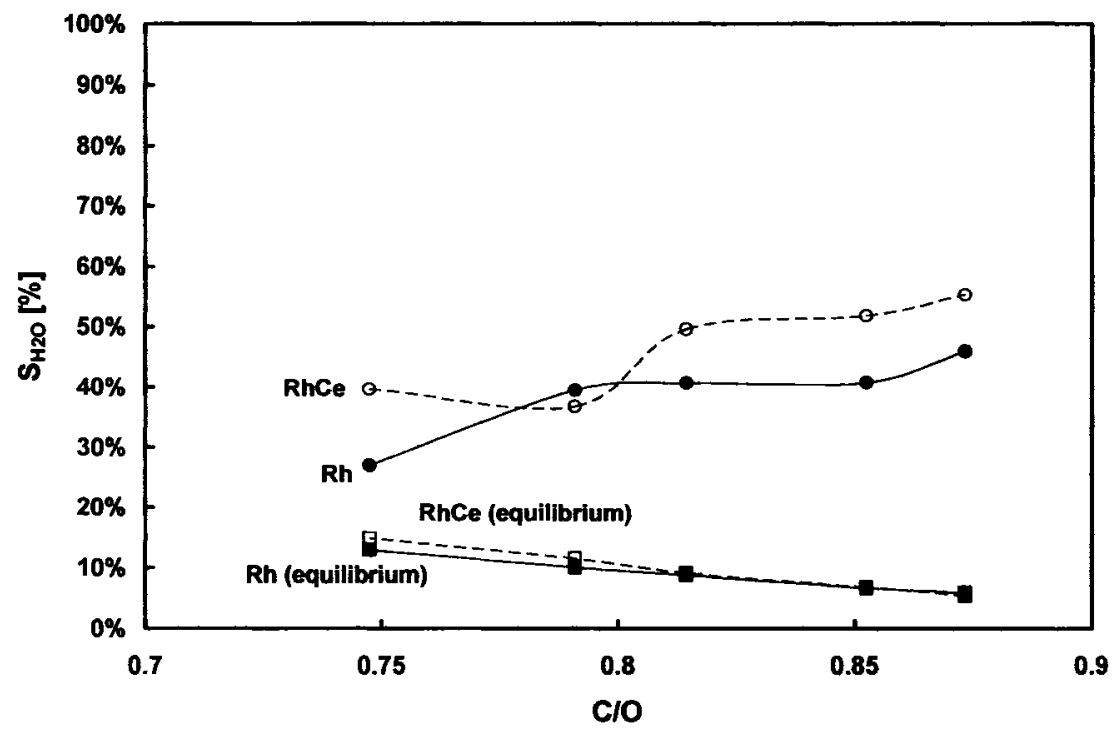

Figure 6: Response of the water selectivity $\left(\mathrm{S}_{\mathrm{H} 2 \mathrm{O}}\right)$ of the $\mathrm{Rh}$ and $\mathrm{RhCe}$ catalysts with respect to the $\mathrm{C} / \mathrm{O}$ ratio 
As it was the case with the hydrogen selectivity, the carbon monoxide selectivity (Figure 7) decreased as the $\mathrm{C} / \mathrm{O}$ feed ratio increased. The Rh catalyst's carbon monoxide selectivity ranges from $36 \%$ to $50 \%$ whereas the RhCe catalyst showed carbon monoxide selectivities between $59 \%$ and $77 \%$. As it was the case for the hydrogen selectivity, the $\mathrm{RhCe}$ catalyst exhibits greater carbon monoxide selectivities than those of the Rh catalyst. On the other hand, the carbon dioxide selectivity (Figure 8) appears to be constant throughout the range of $\mathrm{C} / \mathrm{O}$ ratios studied for both catalysts. The Rh catalyst demonstrated a carbon dioxide selectivity of about $13 \%$ whereas the RhCe catalyst gave a carbon dioxide selectivity of approximately $16 \%$.

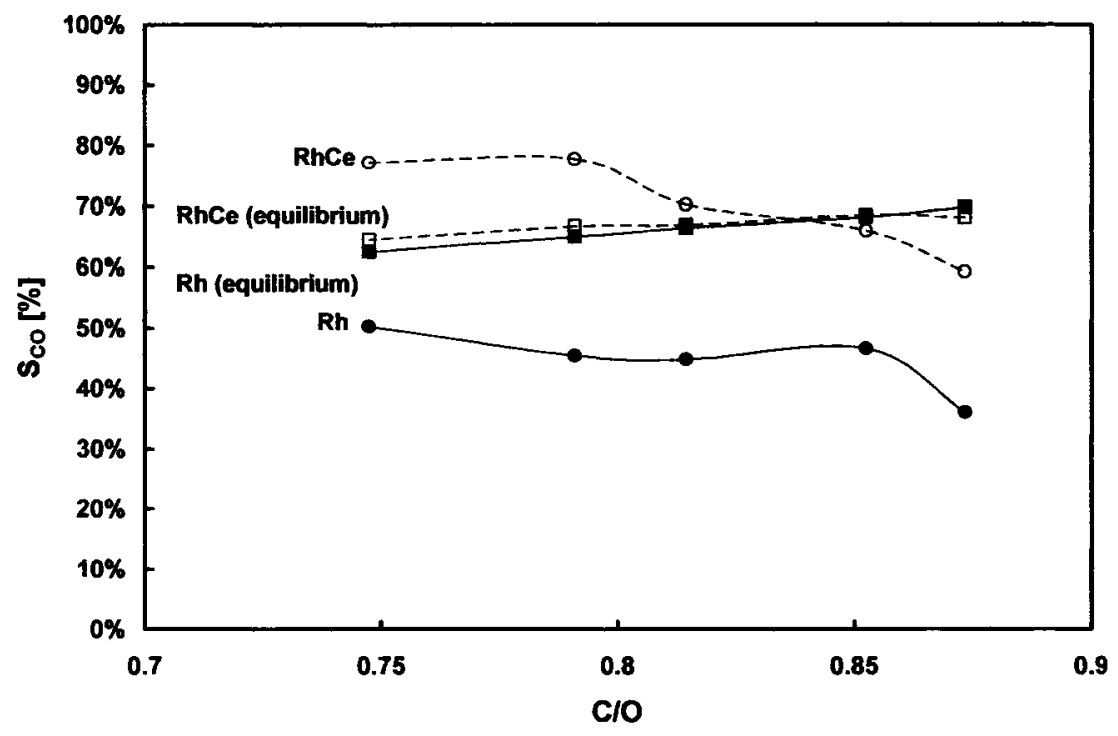

Figure 7: Response of the carbon monoxide selectivity $\left(\mathrm{S}_{\mathrm{co}}\right)$ of the $\mathrm{Rh}$ and $\mathrm{RhCe}$ catalysts with respect to the $\mathrm{C} / \mathrm{O}$ ratio 
Although only the selectivities for $\mathrm{H}_{2}, \mathrm{H}_{2} \mathrm{O}, \mathrm{CO}$, and $\mathrm{CO}_{2}$ were reported, several byproducts were observed and measured from the GC output signal. Those byproducts are ethane, ethylene, acetylene, methanol, acetaldehyde, and methane. Those byproducts are present in the product gas stream in relatively constant quantities for both catalysts throughout the range of $\mathrm{C} / \mathrm{O}$ ratios investigated. Their respective selectivities do not rise above $9 \%$, regardless of the catalyst used. The RhCe catalyst displayed the greater selectivities for most of the byproducts. Conversely, the Rh catalyst showed signs of carbon formation, which was not observed with the RhCe catalyst. Despite the carbon formation, catalyst deactivation was never observed.

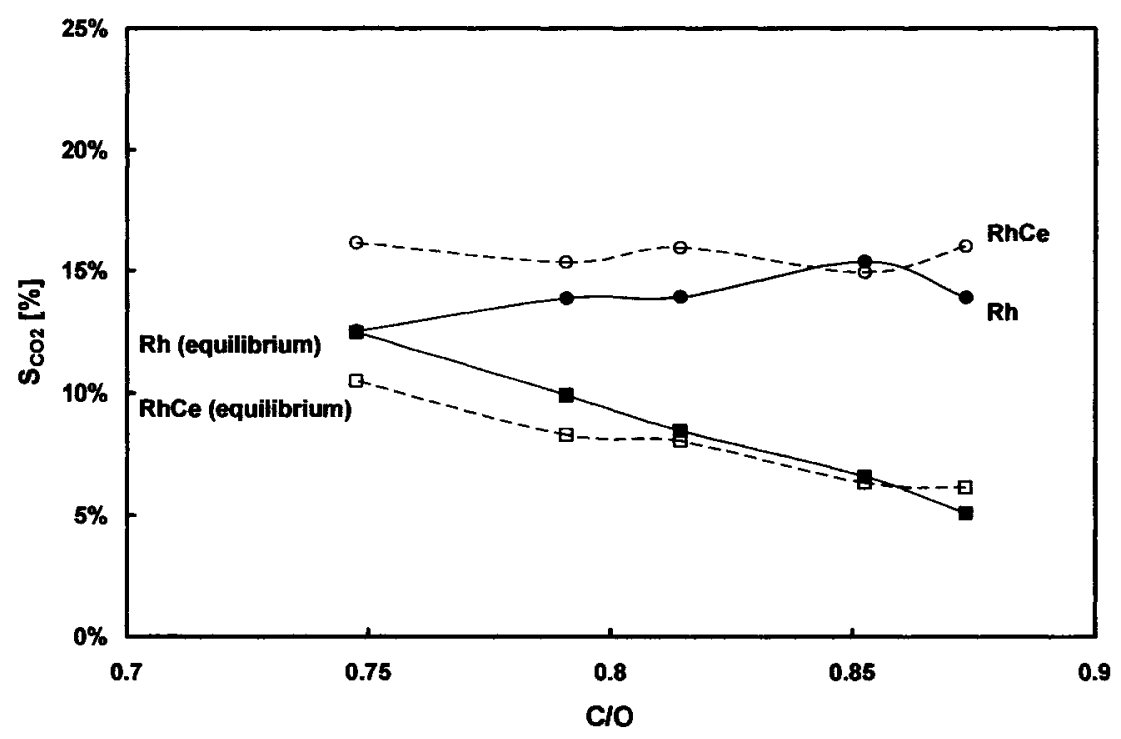

Figure 8: Response of the carbon dioxide selectivity $\left(\mathrm{S}_{\left.\mathrm{CO}_{2}\right)}\right.$ of the $\mathrm{Rh}$ and $\mathrm{RhCe}$ catalysts with the respect to the $\mathrm{C} / \mathrm{O}$ ratio 


\section{Gas Hourly Space Velocity}

As only one GHSV was selected to study the effect of the feed stoichiometry on the reactor performance, a single $\mathrm{C} / \mathrm{O}$ feed ratio $(\mathrm{C} / \mathrm{O}=0.75)$ was picked to graph the results against the entire range of GHSV studied. From the resulting figures, the effect of varying the GHSV is determined. As in the previous subsection, the solid circle $(\bullet)$ symbol represents the experimental results for the Rh catalyst while the hollow circle (o) denotes the experimental results for the RhCe catalyst. It is important to note that the heating tape setting was varied as the GHSV was increased, in order to ensure that the reactor temperature is above the boiling point of methyl acetate. The concern was that the reactor's methyl acetate conversion would be affected by the heating tape setting, which controls the heat input to the reactor in order to vaporize the methyl acetate. A series of experiments were performed at fixed $\mathrm{C} / \mathrm{O}$ feed ratio $(0.75)$ and GHSV (143 $133 \mathrm{~h}^{-1}$ ) in order to ensure that the heating tape setting changes has negligible effect on the reactor performance. Three heating tape settings were used to verify this: $25 \%, 35 \%$, and $45 \%$. It was found that the methyl acetate conversion was not affected by the heating tape setting and hence it is not taken into account as an important reactor parameter.

The back face temperature (Figure 9) for both catalysts was plotted against the GHSV. No distinctive trend could be observed from the Rh catalyst's back face temperature. However, the $\mathrm{RhCe}$ catalyst showed an increasing back face 
temperature in response to the increase in GHSV. The RhCe catalyst demonstrated back face temperatures ranging between $890^{\circ} \mathrm{C}$ and $1120^{\circ} \mathrm{C}$ while the back face temperatures for the $\mathrm{Rh}$ catalyst ranged between $840^{\circ} \mathrm{C}$ and $974^{\circ} \mathrm{C}$.

Figure 10 shows the variation of the oxygen conversion $\left(\mathrm{X}_{\mathrm{O} 2}\right)$ with respect to the GHSV. Both catalysts exhibit similar conversions above $90 \%$. On the other hand, the RhCe catalyst showed a slight increase in $\mathrm{X}_{\mathrm{O} 2}$ as the GHSV rose. On the other hand, the methyl acetate conversions $\left(X_{M A}\right)$ (Figure 11) behave differently. While the Rh catalyst's $X_{M A}$ does not seem to follow any obvious trend, the $\mathrm{RhCe}$ catalyst's $X_{M A}$ increases in response to an increasing GHSV. The $X_{M A}$ varies between $68 \%$ and $92 \%$ for the Rh catalyst, and between $73 \%$ and $94 \%$ for the RhCe catalyst.

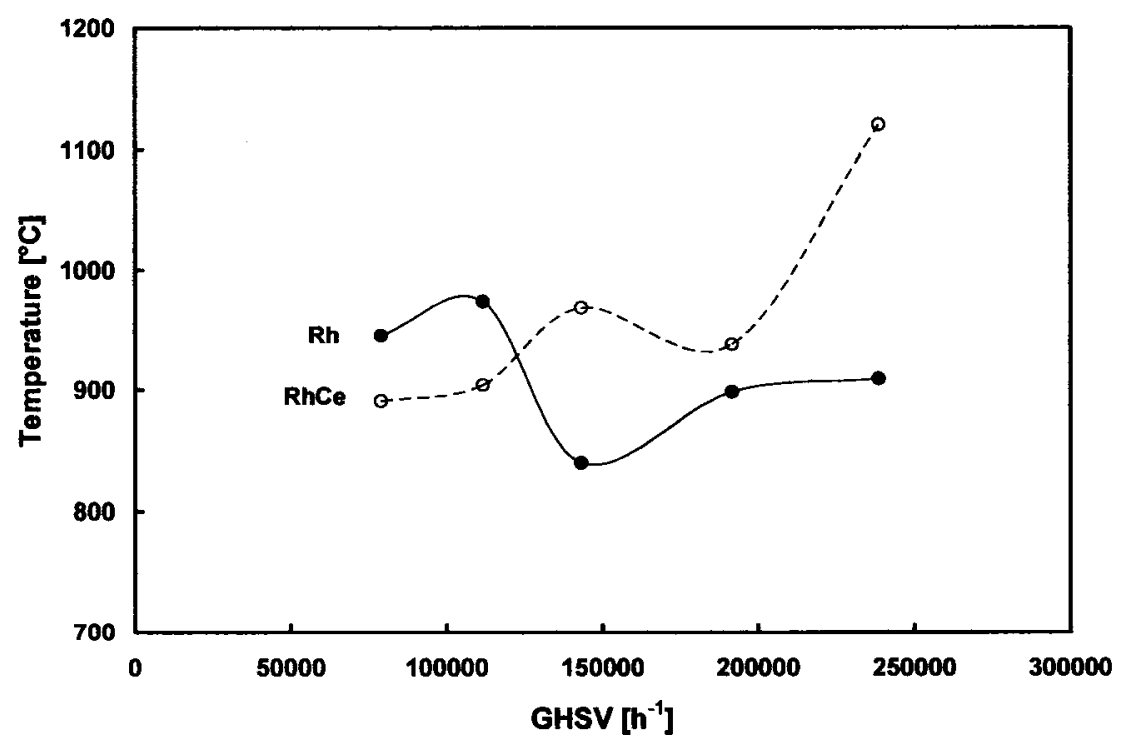

Figure 9:Response of the back face temperature with respect to the GHSV 


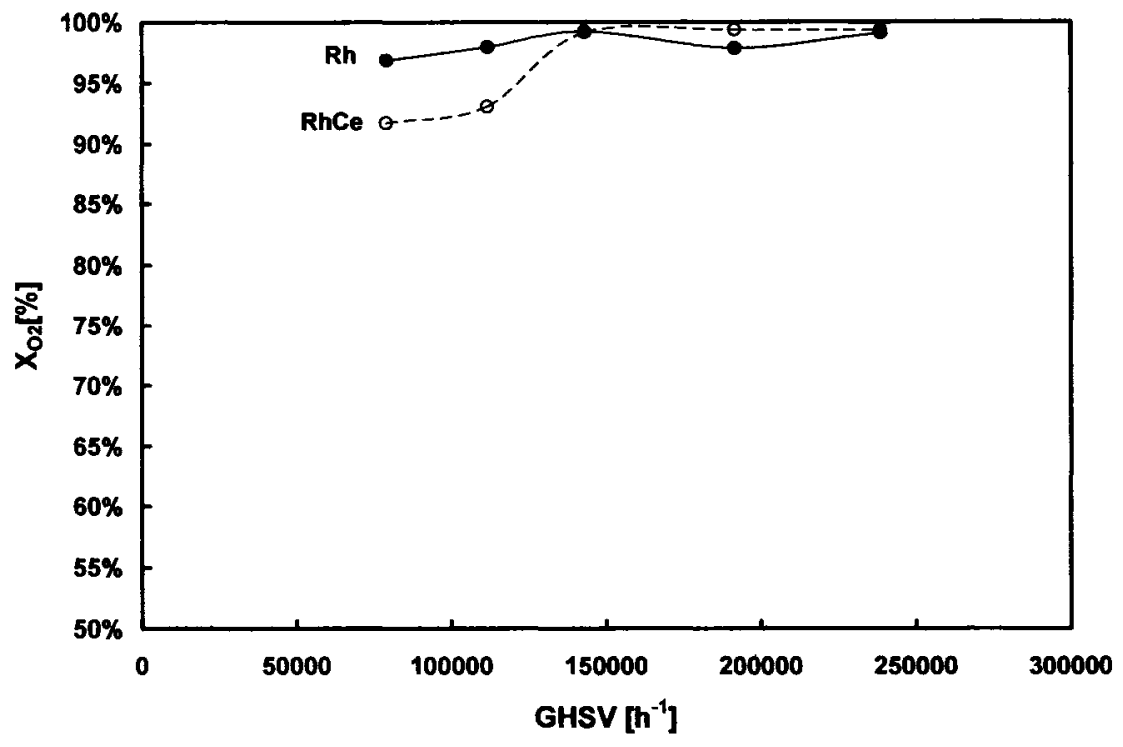

Figure 10: Response of the oxygen conversion $\left(\mathrm{X}_{\mathrm{O} 2}\right)$ with respect to the GHSV

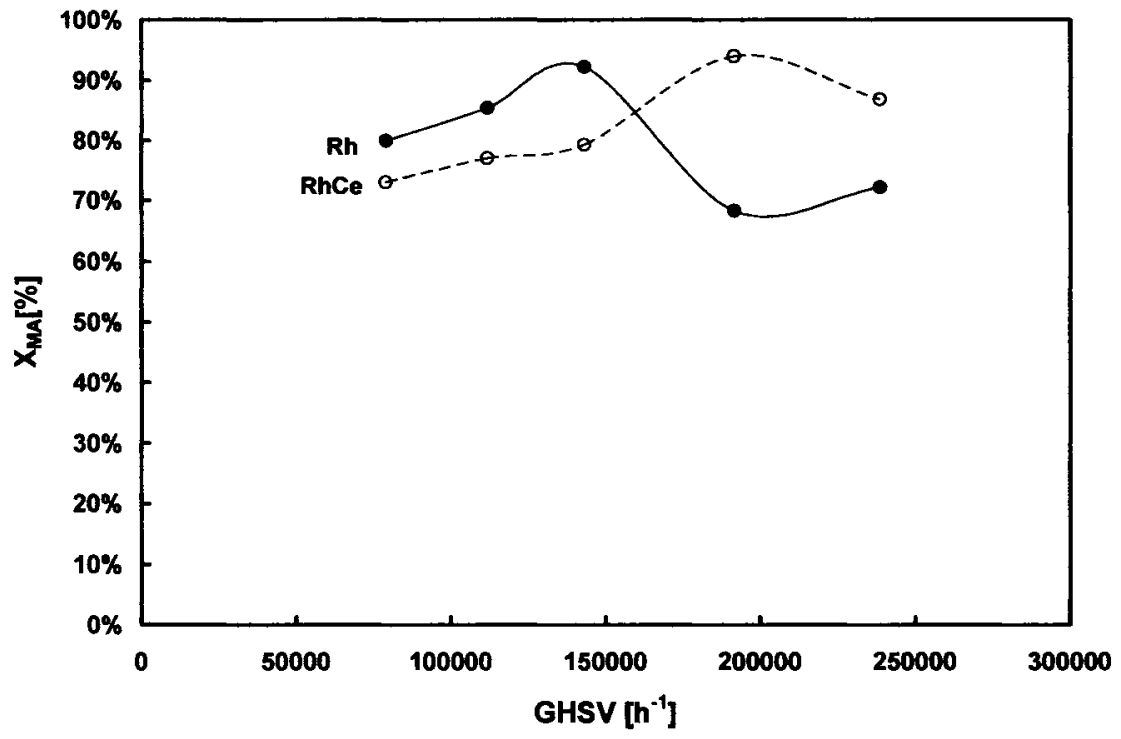

Figure 11: Response of the methyl acetate conversion $\left(X_{M A}\right)$ with respect to the GHSV 


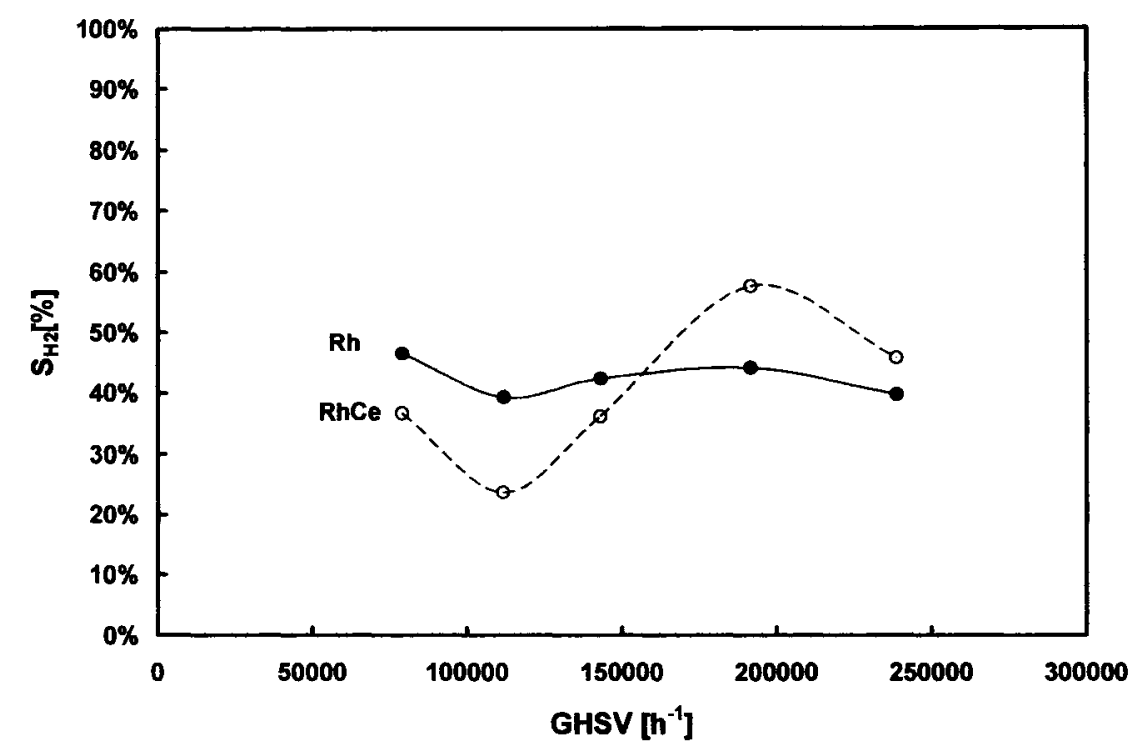

Figure 12: Response of the hydrogen selectivity $\left(\mathrm{S}_{\mathrm{H} 2}\right)$ with respect to the GHSV

Overall, the hydrogen selectivity $\left(\mathrm{S}_{\mathrm{H} 2}\right.$, Figure 12$)$ for both catalysts can be considered constant. The $\mathrm{Rh}$ catalyst demonstrated $\mathrm{S}_{\mathrm{H} 2}$ varying between $39 \%$ and $46 \%$ while the RhCe catalyst's $\mathrm{S}_{\mathrm{H} 2}$ fluctuated between $23 \%$ and $58 \%$ with no noticeable trend. Similarly, both catalysts' water selectivities $\left(S_{\mathrm{H} 2 \mathrm{O}}\right.$, Figure 13$)$ were somewhat constant. The Rh catalyst's $\mathrm{S}_{\mathrm{H} 2 \mathrm{O}}$ varies between $36 \%$ and $45 \%$ while the $\mathrm{S}_{\mathrm{H} 2 \mathrm{O}}$ for the RhCe catalyst ranges between $35 \%$ and $53 \%$.

The carbon monoxide selectivities $\left(\mathrm{S}_{\mathrm{co}}\right)$ for both catalysts are plotted against the GHSV in Figure 14. The Rh catalyst's $S_{C O}$ first decreased from $71 \%$ to a minimum of $62 \%$, and then rises to $82 \%$ over the range of GHSV studied. No trend could be determined from the RhCe catalyst, which oscillated between 
$61 \%$ and $77 \%$. From Figure 15 , both catalysts' carbon dioxide selectivities $\left(\mathrm{S}_{\mathrm{cO} 2}\right)$ are relatively constant over the range of GHSV examined. For the Rh catalyst, the $\mathrm{S}_{\mathrm{CO} 2}$ ranged between $17 \%$ and $22 \%$ while in the case of $\mathrm{RhCe}$, it varied between $14 \%$ and $20 \%$.

The byproducts detected in the product gas stream were the same as in the experiments at constant flow rate, Once again, carbon formation was observed with the use of the Rh catalyst.

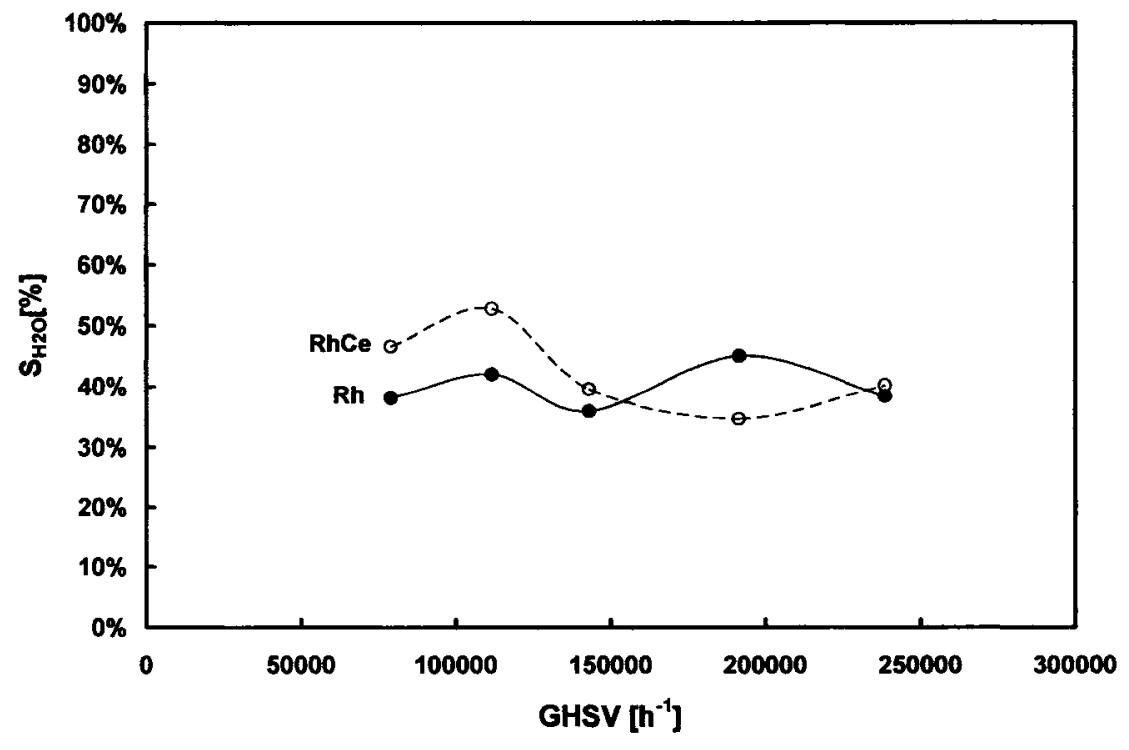

Figure 13: Response of the water selectivity $\left(\mathrm{S}_{\mathrm{H} 2 \mathrm{O}}\right)$ with respect to the GHSV 


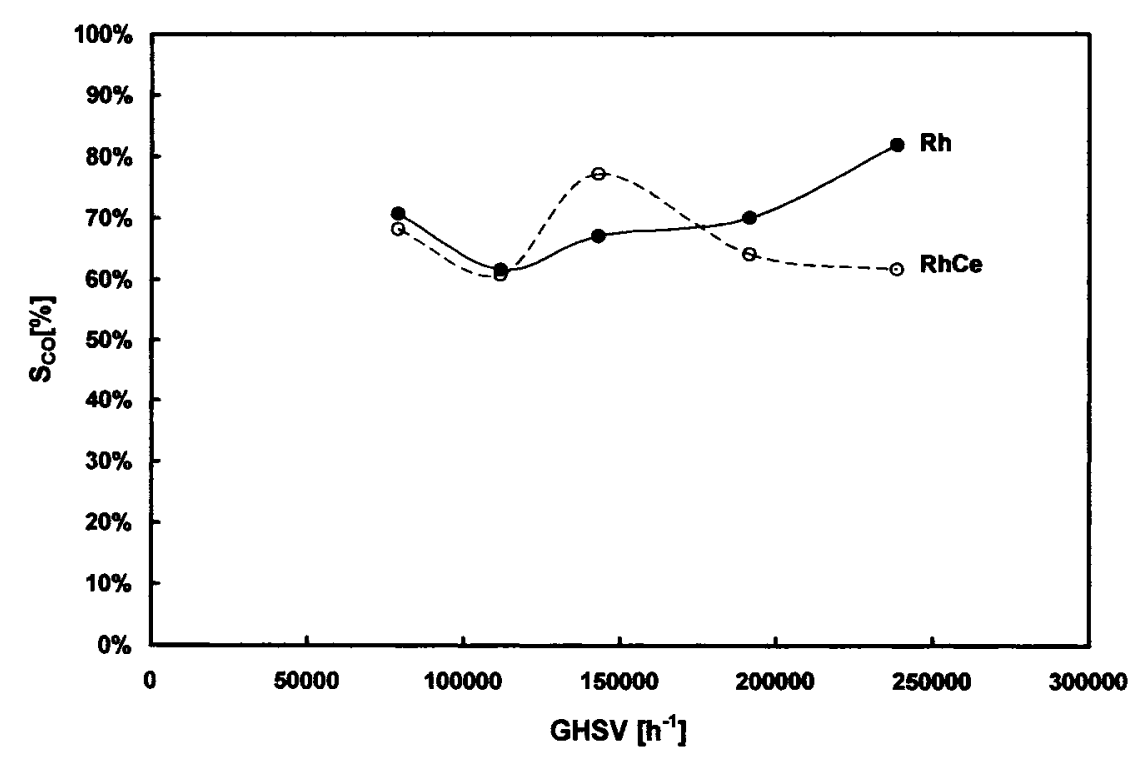

Figure 14: Response of the carbon monoxide selectivity $\left(\mathrm{S}_{\mathrm{CO}}\right)$ with respect to the GHSV

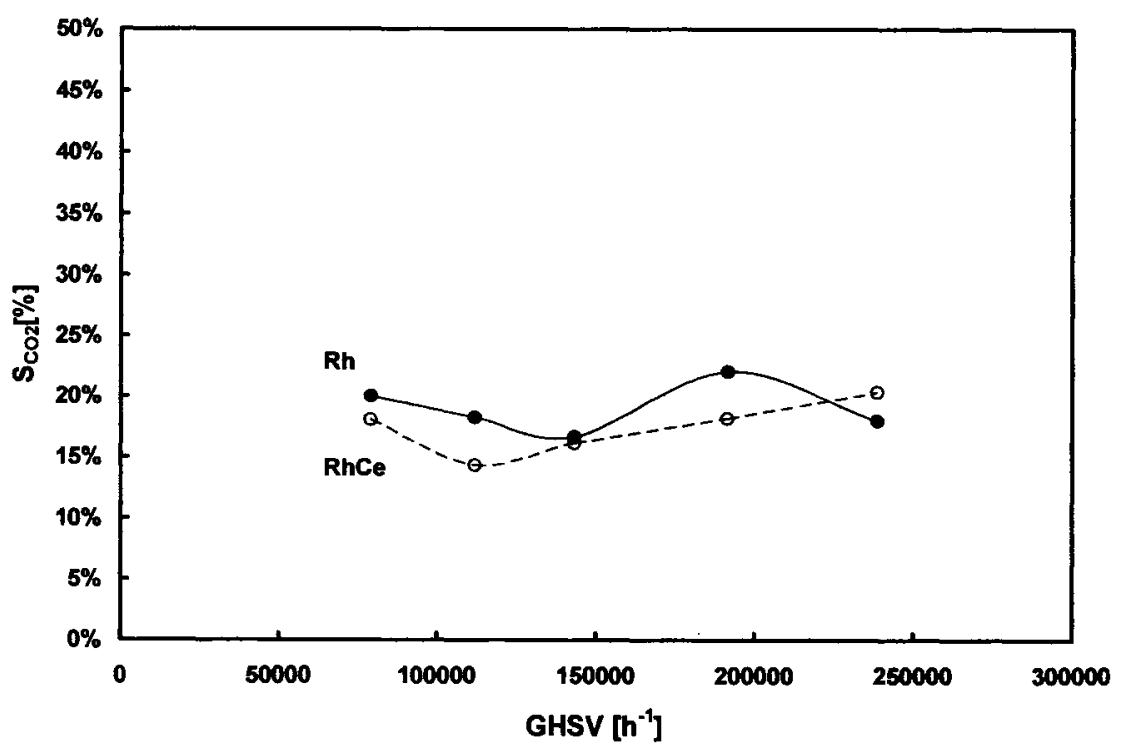

Figure 15: Effect of the carbon dioxide selectivity $\left(\mathrm{S}_{\mathrm{CO} 2}\right)$ with respect to the GHSV 


\section{Equilibrium Composition}

The equilibrium product composition was determined for every set of reactor conditions, in the same manner as described in the Materials and Methods section of this work. The resulting methyl acetate and oxygen conversions were $100 \%$. The product selectivities are plotted against the $\mathrm{C} / \mathrm{O}$ feed ratios and superimposed with the experimental results at constant flow rate in order to compare the two data sets. The colored square ( $\square$ ) represent the calculated product selectivity for the conditions related to the $\mathrm{Rh}$ catalyst (back face temperature and feed conditions) whereas the hollow square ( $\square$ ) denotes the product selectivity for the conditions pertaining to the $\mathrm{RhCe}$ catalyst (back face temperature and feed conditions). The experimental data is represented by the same data point shapes as in the previous subsections. These can be found in Figure 5, Figure 6, Figure 7, and Figure 8.

\section{Comparison to Biodiesel Results}

A set of experiments at a constant gas flow rate of $4 \mathrm{slpm}\left(\mathrm{GHSV}=127300 \mathrm{~h}^{-1}\right.$ ) was performed in order to obtain the $X_{M A}$ and product selectivities, which can be compared to those reported in a previous publication on the CPO of biodiesel [34]. The $X_{M A}$ is plotted in Figure 16 whereas $S_{H 2}, S_{H_{2} O}, S_{C O}$, and $S_{\mathrm{CO}_{2}}$ are respectively plotted in Figure 17, Figure 18, Figure 19, and Figure 20. 
The same trends in the methyl acetate conversion and product selectivities were observed as in the constant GHSV experiments. The methyl acetate conversion dropped from $81 \%$ to $62 \%$ as the $\mathrm{C} / \mathrm{O}$ ratio increased. The hydrogen selectivity decreased from $39 \%$ to $18 \%$ while the water selectivity rose from $36 \%$ to $43 \%$. The carbon monoxide selectivity fell from $78 \%$ to $64 \%$ as the carbon dioxide selectivity stayed around $14-15 \%$.

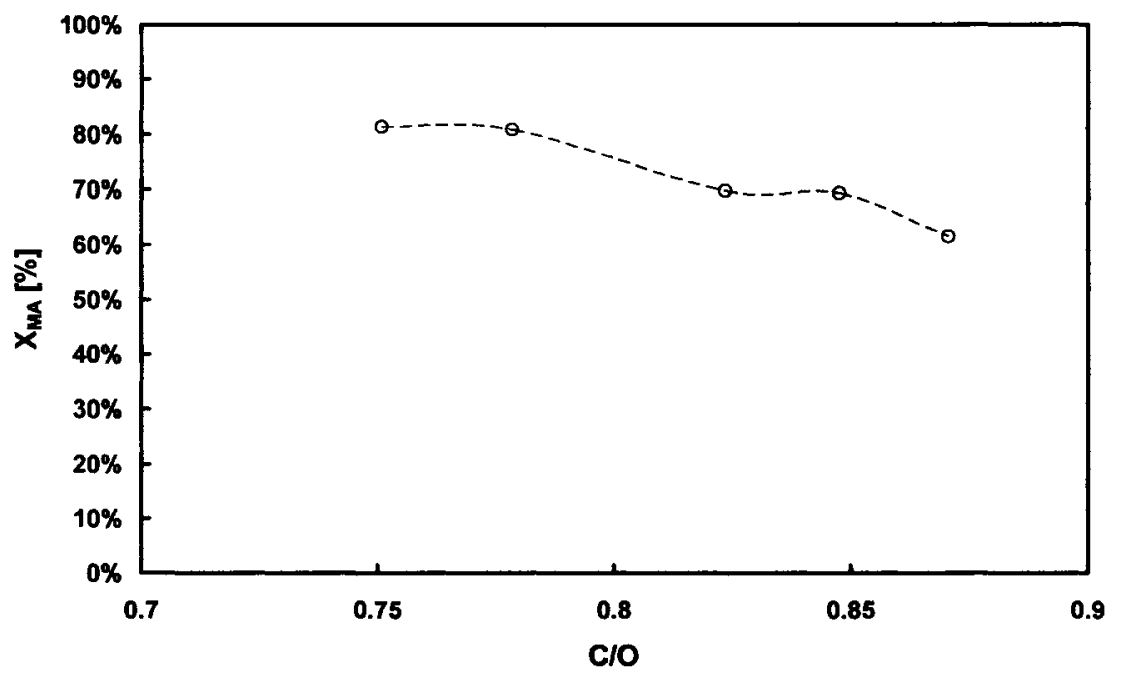

Figure 16: Methyl acetate conversion $\left(\mathrm{X}_{\mathrm{MA}}\right)$ versus $\mathrm{C} / \mathrm{O}$ ratio 


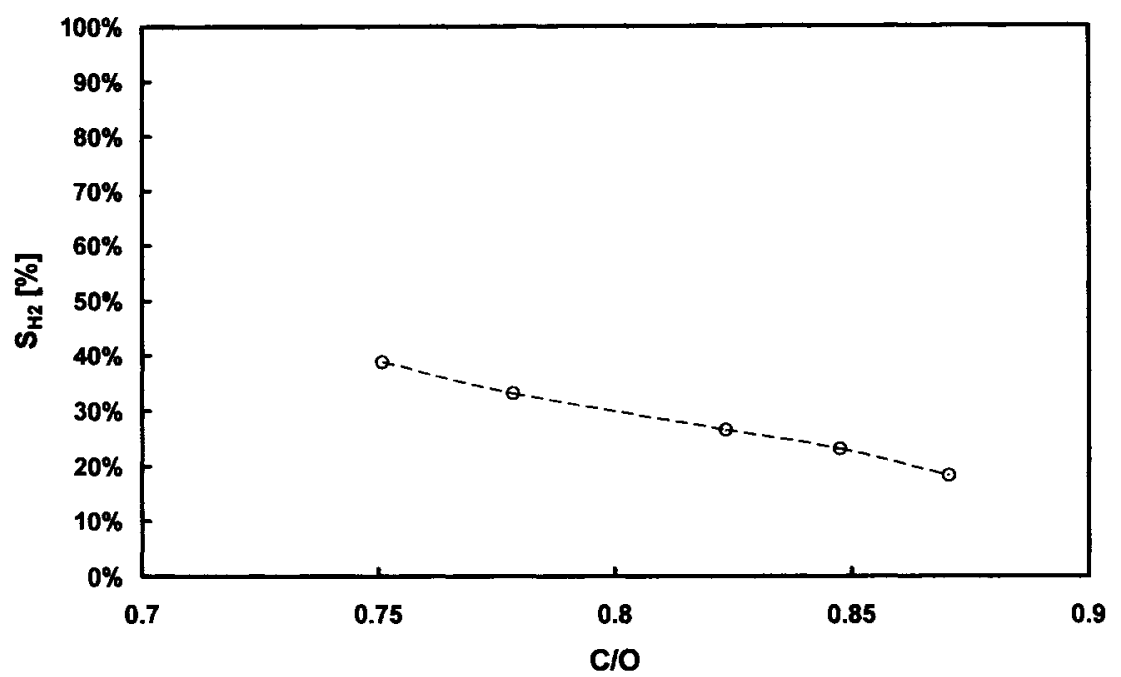

Figure 17: Hydrogen selectivity $\left(\mathrm{S}_{\mathrm{H} 2}\right)$ versus $\mathrm{C} / \mathrm{O}$ ratio

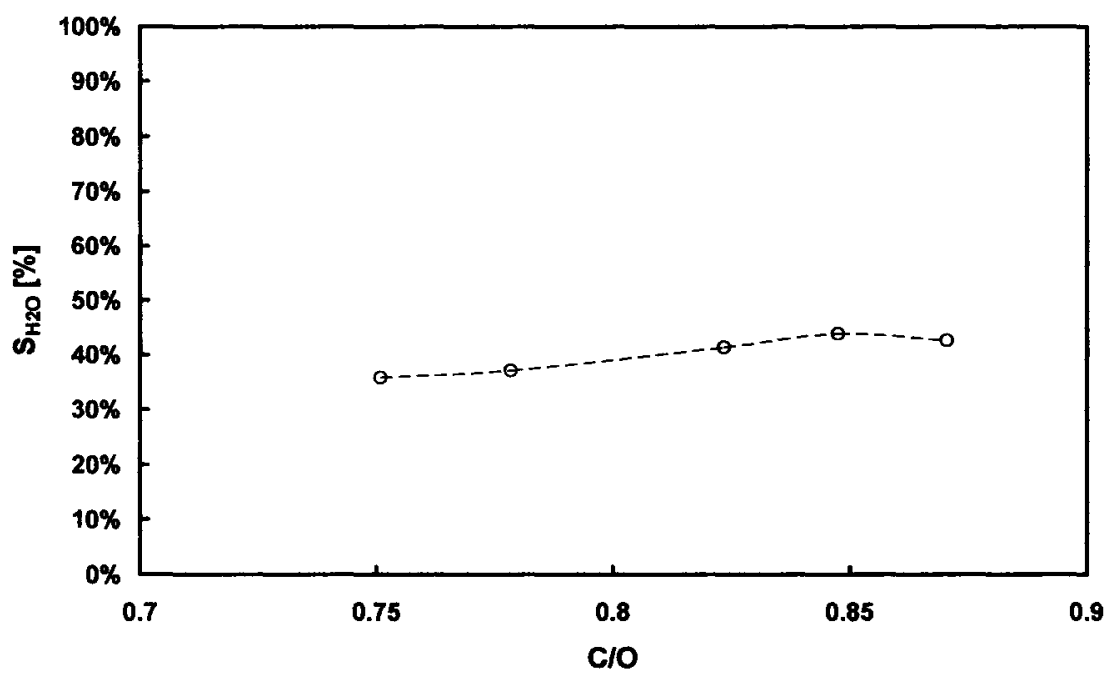

Figure 18: Water selectivity $\left(\mathrm{S}_{\mathrm{H} 2 \mathrm{O}}\right)$ versus $\mathrm{C} / \mathrm{O}$ ratio 


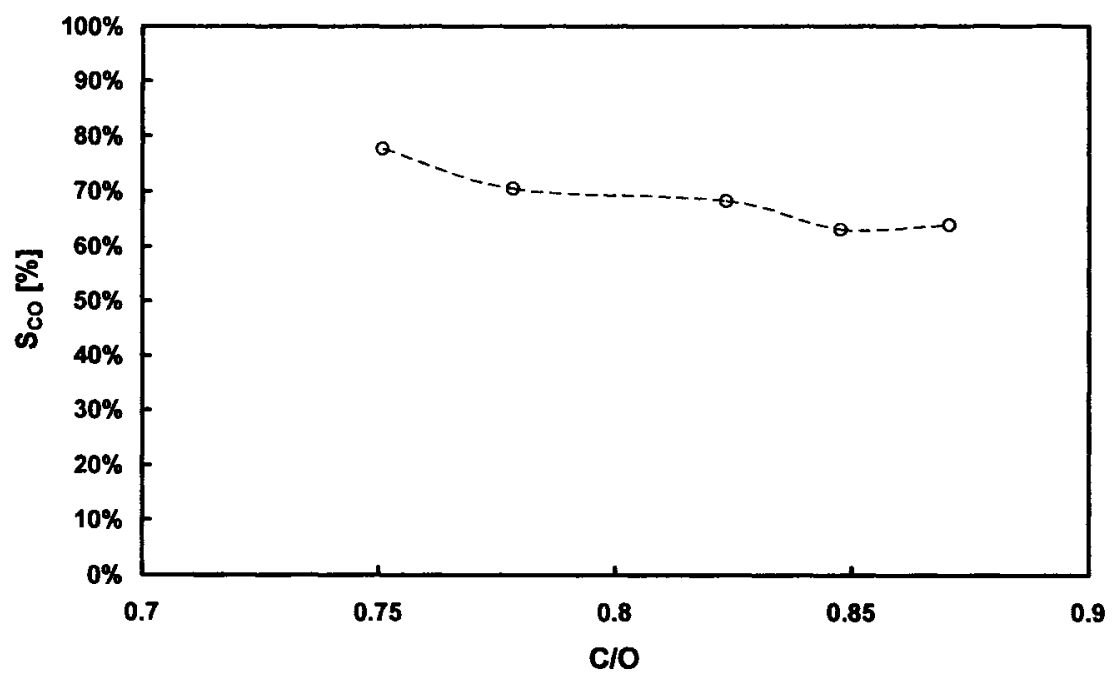

Figure 19: Carbon monoxide selectivity $\left(S_{c o}\right)$ versus $\mathrm{C} / \mathrm{O}$ ratio

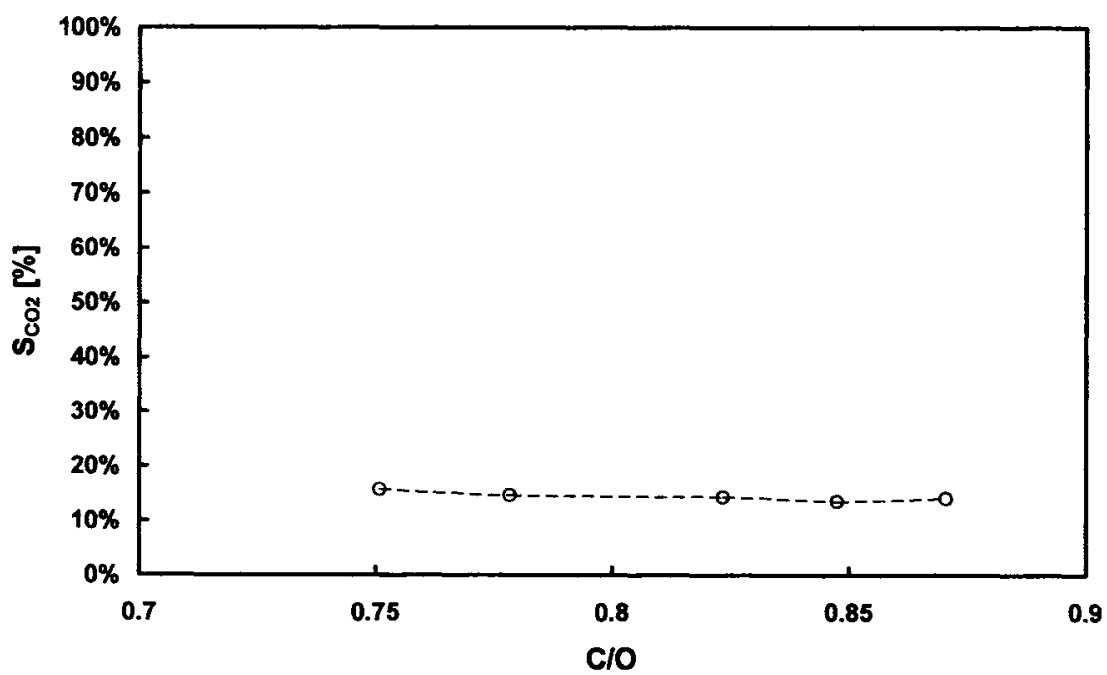

Figure 20: Carbon dioxide selectivity $\left(\mathrm{S}_{\mathrm{CO} 2}\right)$ versus $\mathrm{C} / \mathrm{O}$ ratio 


\section{Technical Difficulties}

In order to determine the reactor product stream's composition, product gas samples were repeatedly injected into a GC. As previously mentioned, the product gas stream contains a great variety of byproducts along with unreacted methyl acetate and carbon particles. Methyl acetate and methanol are mildly acidic compounds. However, the presence of unreacted methyl acetate in the product gas stream increased greatly in certain experiments. Since the GC's PLOT Q column is sensitive to organic acids, this caused several problems to the instrument. The acidic compounds in the product gas stream caused corrosion in the injection port and at the graphite junction between the two columns and damage to the bonded phase of the column. All these damages resulted in the breakdown of the GC, after months of operation. The non-negligible presence of water in the product gas stream may have caused some long-term damage to the $T C D$, although this was not observed during an inspection of the GC following the breakdown. Furthermore, the carbon particles present in the product gas sample were trapped in the GC's injection port and acted as a retention compound. As a result, some of the organic compounds present in the gas samples were retained by the carbon particles and they were released and detected during blank runs. This creates some false positives in the results. However, this problem only affects the hydrocarbon analysis and all major reactor products were actually permanent gases. The hydrocarbons and oxygenates were only present in very small amounts. Also, some of the compounds in the product gas stream have 
condensed and some carbon particles have remained trapped in the syringe's barrel. The syringe's plunger slowly became harder to handle and solid black particles appeared at the bottom of the barrel.

There were several possible ways to either prevent or elminate these problems. One possible solution is to remove the carbon particles from the gas sample, collect a gas sample in a gas bag and inject the analysis samples from the bag. Secondly, a liner with no packing material can be used in the GC and the PLOT Q column can be substituted with another column, which can handle more polar compounds. Lastly, a periodic back-flush of the two GC columns is recommended. 


\section{Discussion}

\section{Rhodium versus Rhodium-Ceria}

After examining the graphs of experimental data at constant GHSV, it was observed that the use of a RhCe catalyst leads to higher back face temperatures, higher $S_{\mathrm{H} 2}$, and higher $S_{\mathrm{CO}}$ than the use of a Rh catalyst. The presence of the ceria may explain this improvement in the reactor performance. Ceria is known to be an important additive in the preparation of catalysts used for the control of automotive exhaust emissions [51]. Ceria's most remarkable property is its ability to store and release oxygen. Cerium possesses two stable oxidation states $\left(\mathrm{Ce}^{3+}\right.$ and $\left.\mathrm{Ce}^{4+}\right)$, which existence allows for the ceria to shift between $\mathrm{CeO}_{2}$ and $\mathrm{Ce}_{2} \mathrm{O}_{3}$ based on the presence or absence of oxygen. In an oxygen-rich environment, the ceria will oxidize and therefore it will store oxygen in its lattice structure. Conversely, the ceria will undergo reduction in oxygen-deficient conditions and it will then release some lattice oxygen [52]. As a result of this oxygen storage property, ceria has been shown to promote the water gas shift reaction (2) [53]. Even though the reactor performance is affected by the presence of ceria in the catalyst, the improvement in the reactor's performance is not as significant as discovered for the CPO of other fuels [31, 54]. 


\section{Mechanism}

As described in a previous section, the CPO of methane was found to be in fact a two-step reaction $[5,26,29]$. If a similar mechanism is appropriate to describe the CPO of methyl acetate, the first step of the reaction would be the depletion of the oxygen present in the feed stream through the combustion of methyl acetate (9). The combustion is believed to occur within the first millimeter at the entrance of the catalyst [34]. The combustion reaction will produce carbon dioxide and water, which will be used as reactants in the second reaction step. The second step in the CPO of methyl acetate is the steam reforming and dry reforming of the remaining methyl acetate.

$$
\begin{array}{ll}
\mathrm{C}_{3} \mathrm{H}_{6} \mathrm{O}_{2}+\mathrm{H}_{2} \mathrm{O} \rightarrow 3 \mathrm{CO}+4 \mathrm{H}_{2} & \Delta \mathrm{H}=320.2 \mathrm{~kJ} \cdot \mathrm{mol}^{-1} \\
\mathrm{C}_{3} \mathrm{H}_{6} \mathrm{O}_{2}+\mathrm{CO}_{2} \rightarrow 4 \mathrm{CO}+3 \mathrm{H}_{2} & \Delta \mathrm{H}=361.4 \mathrm{~kJ} \cdot \mathrm{mol}^{-1}
\end{array}
$$

From this concept, it can be deduced that an increase of the $\mathrm{C} / \mathrm{O}$ ratio will involve less oxygen being fed to the reactor. The fact that there is less oxygen available in the feed suggests that there is less combustion of the methyl acetate entering the reactor. Since there is less combustion, less heat is produced and therefore the catalyst's back face temperature is lower. Consequently, the reforming reactions will occur at a lesser extent. Lower $\mathrm{S}_{\mathrm{H} 2}$ and greater $\mathrm{S}_{\mathrm{H} 2 \mathrm{O}}$ are observed as a result. The reduction in the extent of the reforming reactions may explain why an increase in $\mathrm{C} / \mathrm{O}$ ratios generates a continuous decrease in $\mathrm{S}_{\mathrm{CO}} . \mathrm{S}_{\mathrm{CO} 2}$ is relatively constant throughout the range of feed ratios studied. This suggests two 
possible situations: either the rate of dry reforming (11) is independent of the catalyst temperature within the range studied, or $\mathrm{CO}_{2}$ is basically not produced in large amounts. This suggests that the primary reaction would be a conversion of the methyl acetate into $\mathrm{H}_{2} \mathrm{O}$ and $\mathrm{CO}$ instead of $\mathrm{H}_{2} \mathrm{O}$ and $\mathrm{CO}_{2}$. Since the reforming reactions are not favored by the catalyst's temperature, the unreacted methyl acetate may undergo side reactions to form byproducts such as acetaldehyde, methanol, ethanol, methane, ethane, ethylene, and acetylene.

The FactSage software computed equilibrium product compositions, which trends in product selectivities (see Figure 5, Figure 6, Figure 7, and Figure 8) are contrary to those found with experimental data at constant GHSV. This finding suggests that the reactor is obviously not operating at the thermodynamic equilibrium state. While the methyl acetate conversions computed by FactSage show a constant linear trend at $100 \%$, the experimentally determined methyl acetate conversion actually decreases for both catalysts over the range of $\mathrm{C} / \mathrm{O}$ ratios. As the contact time is very small, the reactor is not allowed the required time to attain equilibrium. Hence the primary reactions are favored and chain reactions are inhibited [55]. In this work, the CPO is assumed to be a two-step process, with combustion as the primary step followed by the reforming and water-gas shift reactions. The observed reactor product composition is reasonably closer to that of combustion products. This product composition as well as the increasing $\mathrm{C} / \mathrm{O}$ ratio will cause the methyl acetate conversion, $\mathrm{S}_{\mathrm{H} 2}$, 
and $S_{\mathrm{CO}}$ to decrease, while $\mathrm{S}_{\mathrm{H} 2 \mathrm{O}}$ and $\mathrm{S}_{\mathrm{CO} 2}$ would increase. The experimental values for $S_{\mathrm{H} 2 \mathrm{O}}$ are greater than those determined from the equilibrium product data, as $\mathrm{H}_{2} \mathrm{O}$ is an intermediate product in the CPO reaction. Since the combustion products are not present in stoichiometric amounts, it can be deduced that there is some reforming and water-gas shift reactions occurring in the reactor.

Furthermore, it is important to note that the catalyst's back face temperature was used for FactSage computations. As a result of the initial total oxidation and subsequent reforming of the methyl acetate, the catalyst's front face temperature is significantly greater than the back face temperature. There exists a considerable temperature profile within the catalyst [56]. This implies that the equilibrium product compositions are calculated from temperatures lower than the actual temperatures inside the catalyst.

\section{Effects of Heat and Mass Transfer}

In the experiments at constant feed stoichiometry, the methyl acetate conversion appears to reach a maximum value at some point in the range of total gas flow rates studied. This was observed for both catalysts. Although there is no report of studies demonstrating this, it is thought that the peak in methyl acetate 
conversion is a result of the reactor's transition from a heat transfer-limited to a mass transfer-limited regime [43].

As it was previously explained, the CPO of methyl acetate is believed to occur as a two-step process. The heat generated by the initial combustion of methyl acetate supplies for the heat requirements of the succeeding reforming reactions and this allows for the autothermal operation of the reactor. A heat transfer limitation implies that the transfer of the heat of combustion from the catalyst's front face to the remainder of the catalyst does not occur at a sufficiently high rate. This would occur at the lower GHSV values. The catalyst would exhibit a temperature profile with a considerable reduction from the entrance region to the catalyst's back face. As a result, the reforming reactions, which convert the excess methyl acetate from the initial combustion reaction, may not take place over the catalyst volume. While the Rh catalyst's experimental data shows too much variation to support this idea, the RhCe catalyst's experimental data illustrates a continuous increase in back face temperature as the GHSV increases. While the back face temperature rises, the methyl acetate conversion is expected to increase since the heat transfer and the reaction kinetics are improved. However, the reactor's contact time decreases as the GHSV increases and at some point the contact time becomes too small for the reactants to be transported to the catalyst's surface. Hence a drop in methyl acetate conversion is observed at the upper end of the GHSV range studied, in spite of the sharp 
increase in back face temperature. Also, the decrease in $\mathrm{S}_{\mathrm{H} 2}$ at high GHSV is a sign that there is less reforming in the reactor. This leads to smaller methyl acetate conversions and lower yields of hydrogen.

\section{Comparison to Biodiesel Results}

Previous literature has reported CPO experiments conducted with soybean oilderived biodiesel at a total gas flow rate of 4 slpm [34]. These experiments were replicated for methyl acetate in the most similar manner as possible. Since biodiesel is a mixture of various long-chain ester compounds, an average number of carbon atoms per molecule, over the mixture was used to calculate a $\mathrm{C} / \mathrm{O}$ feed ratio. As methyl acetate is a much smaller ester compound, the $\mathrm{C} / \mathrm{O}$ feed ratios for CPO and combustion do not correspond with those of biodiesel. Despite this, it is clear from the comparison between the methyl acetate experiments and the biodiesel data reported by Subramanian and Schmidt that the use of a simple methyl ester molecule such as methyl acetate does not yield similar fuel conversions and product selectivities to the biodiesel mixture. The use of methyl acetate in a CPO reactor similar to that previously used for biodiesel yielded considerably lower fuel conversions and hydrogen selectivities. However, the reason behind this is not yet understood. This indicates that the methyl ester functional group may not readily decompose to syngas components over a $\mathrm{RhCe}$ catalyst. The typical biodiesel molecule possesses a considerably longer carbon chain attached to the methyl ester functional group and as a result, it may be 
more reactive. Conversely, methyl acetate has a methyl group bonded to the ester functional group and thus it is a more stable molecule. While $\mathrm{Rh}$ and $\mathrm{RhCe}$ demonstrate some synthesis gas activity, a more suitable catalyst should be used. The catalyst could be either a single catalytic metal or a mixture of catalytic metals selected to target various specific functional groups. For example, research has shown that $\mathrm{RhCe}$ is a suitable catalyst for CPO of alkanes [20]. Since it has shown some synthesis gas activity for the CPO of methyl acetate, it could be combined with another metal in order to improve the acetate's decomposition to synthesis gas. 


\section{Conclusions}

The experimental data imply that the methyl acetate undergoes an initial combustion, followed by some reforming and water-gas shift. An increasing $\mathrm{C} / \mathrm{O}$ feed ratio was found to cause a decrease in the amount of combustion products made available for the reforming and water-gas shift reactions. This entails a decrease in the methyl acetate conversion, the hydrogen selectivity, and the carbon monoxide selectivity. As a result, there is a greater amount of methyl acetate, which undergoes side reactions to form various byproducts. Furthermore, the experiments at constant feed stoichiometry suggest that the reactor undergoes a transition from a heat transfer-limited regime to a mass transfer-limited regime, as the GHSV increases. This is in agreement with previous studies indicating heat and mass transfer limitations.

In this work we have shown that rhodium-ceria yields slightly higher methyl acetate conversion, hydrogen selectivity, and carbon monoxide selectivity. The presence of ceria promotes the water-gas shift reaction, which converts the CO and $\mathrm{H}_{2} \mathrm{O}$ formed through the combustion step of the partial oxidation process into $\mathrm{CO}_{2}$ and $\mathrm{H}_{2}$, and hence contributes in the higher yield of $\mathrm{H}_{2}$. However, the effect of the ceria is not as significant for the CPO of methyl acetate as it was shown to be for the CPO of other fuels. 
According to the comparison of the experimental data to an equilibrium product composition as calculated by FactSage, the reactor does not operate at the thermodynamic equilibrium state. The catalyst back face temperature was used as the reactor temperature in the FactSage calculations. However, a temperature profile exists within the catalyst and as a result, the calculated equilibrium product compositions differ from those observed during experiments conducted. Since the reactor is not operating at the equilibrium state, the process' primary reactions are favored and intermediate products are therefore observed.

Finally, the CPO of methyl acetate was found to yield lower fuel conversions and product selectivities than those reported for biodiesel in a previous publication [34]. The methyl ester functional group is yet to be thoroughly investigated. Since the methyl ester functional group and not the hydrocarbon chain limits the yield of hydrogen, new catalysts should be developed and investigated to better target the decompositon of methyl esters into hydrogen. 


\section{References}

1. Shaine Tyson, K., 2004 Biodiesel Handling and Use Guidelines, U.S. Department of Energy, Editor. 2004, U.S. Department Of Energy.

2. Fuel Cell Handbook. 2000, U.S. Department of Energy.

3. NOx: How nitrogen oxides affect the way we live and breathe, Office of Air Quality Planning and Standards, Editor. 1998, United States Environmental Protection Agency.

4. HFCIT Hydrogen Production: Natural Gas Reforming. 2006 October 24, 2006 [cited 2006 November 5, 2006]; Available from: http://www.eere.energy.gov/hydrogenandfuelcells/production/natural gas.html.

5. Tong, G.C.M., J. Flynn, and C.A. Leclerc, $A$ dual catalyst bed for the autothermal partial oxidation of methane to synthesis gas. Catalysis Letters, 2005. 102(3-4): p. 131-137.

6. Rioche, C., et al., Steam reforming of model compounds and fast pyrolysis bio-oil on supported noble metal catalysts. Applied Catalysis B: Environmental, 2005. 61: p. 130-139.

7. Hickman, D.A., E.A. Haupfear, and L.D. Schmidt, Synthesis gas formation by direct oxidation of methane over Rh monoliths. Catalysis Letters, 1993. 17: p. 223-237. 
8. Deluga, G.A., et al., Renewable Hydrogen from Ethanol by Autothermal Reforming. Science, 2004. 303: p. 993-997.

9. Traxel, B.E. and K.L. Hohn, Partial oxidation of methanol at millisecond contact times. Applied Catalysis A: General, 2003. 244: p. 129-140.

10. R. Subramanian, L.D.S., Renewable Olefins from Biodiesel by Autothermal Reforming. Angewandte Chemie International Edition, 2005. 44: p. 302-305.

11. Van Gerpen, J., Biodiesel processing and production. Fuel Processing Technology, 2005. 86: p. 1097-1107.

12. EGG Technical Services Inc., Fuel Cell Handbook. 2004, U.S. Department of Energy,.

13. Krigmont, H.V. The formation of NOx. 1999 October 30, 1999 [cited 2006 December 5, 2006]; $\quad$ Available http://www.alentecinc.com/papers/NOx/The $\% 20$ formation $\% 20$ of $\% 20$ NOx files $/ \mathrm{Th}$ e\%20formation\%20of\%20NOx.htm.

14. U.S. Department of Energy. Biomass Program: Catalytic Conversion. 2006 March 14, 2006 [cited 2006 December 7]; Available from: http://www1.eere.energy.gov/biomass/catalytic conversion.html.

15. Reyes, S.C., J.H. Sinfelt, and J.S. Feeley, Evolution of Processes for Synthesis Gas Production: Recent Developments in an Old Technology. 
Industrial \& Engineering Chemistry Research, 2003. 42: p. 1588-1597.

16. Kolb, G., et al., Propane steam reforming in micro-channels - results from catalyst screening and optimisation. Applied Catalysis A: General, 2004. 277: p. 155-166.

17. Hickman, D.A. and L.D. Schmidt, Production of Syngas by Direct Catalytic Oxidation of Methane. Science, 1993. 259(5093): p. 343-346.

18. Hickman, D.A. and L.D. Schmidt, Synthesis gas formation by direct oxidation of methane over Pt monoliths. Journal of Catalysis, 1992. 138: p. 267282.

19. Song, X. and Z. Guo, Technologies for direct production of flexible $\mathrm{H}_{2} / \mathrm{CO}$ synthesis gas. Energy Conversion and Management, 2006. 47: p. 560-569.

20. Degenstein, N.J., R. Subramanian, and L.D. Schmidt, Partial oxidation of n-hexadecane at short contact times: Catalyst and washcoat loading and catalyst morphology. Applied Catalysis A: General, 2006. 305: p. 146-159.

21. Subramanian, R., et al., Catalytic partial oxidation of higher hydrocarbons: reactivities and selectivities of mixtures. Chemical Engineering Science, 2004. 59: p. 5501-5507.

22. O'Connor, R.P., et al., Tuning millisecond chemical reactors for the catalytic partial oxidation of cyclohexane. Applied Catalysis A: General, 2003. 238: p. $29-40$ 
23. Krummenacher, J.J., K.N. West, and L.D. Schmidt, Catalytic partial oxidaton of higher hydrocarbons at millisecond contact times: decane, hexadecane, and diesel fuel. Journal of Catalysis, 2003. 215: p. 332-343.

24. O'Connor, R.P., E.J. Klein, and L.D. Schmidt, High yields of synthesis gas by millisecond partial oxidation of higher hydrocarbons. Catalysis Letters, 2000. 70: p. 99-107.

25. Bodke, A.S., S.S. Bharadwaj, and L.D. Schmidt, The Effect of Ceramic Supports on Partial Oxidation of Hydrocarbons over Noble Metal Coated Monoliths. Journal of Catalysis, 1998. 179: p. 138-149.

26. Mallens, E.P.J., J.H.B.J. Hoebink, and G.B. Marin, The Reaction Mechanism of the Partial Oxidation of Methane to Synthesis Gas: A Transient Kinetic Study over Rhodium and a Comparison with Platinum. Journal of Catalysis, 1997. 167: p. 43-56.

27. Torniainen, P.M., X. Chu, and L.D. Schmidt, Comparison of MonolithSupported Metals for the Direct Oxidation of Methane to Syngas. Journal of Catalysis, 1994. 146: p. 1-10.

28. Schmidt, L.D. and M. Huff, Partial oxidation of $\mathrm{CH}_{4}$ and $\mathrm{C}_{2} \mathrm{H}_{6}$ over noble metal-coated monoliths. Catalysis Today, 1994. 21: p. 443-454.

29. Buyevskaya, O.V., D. Wolf, and M. Baerns, Rhodium-catalyzed partial oxidation of methane to $\mathrm{CO}$ and $\mathrm{H}_{2}$. Transient studies on its mechanism. 
Catalysis Letters, 1994. 29: p. 249-260.

30. Wanat, E.C., B. Suman, and L.D. Schmidt, Partial oxidation of alcohols to produce hydrogen and chemicals in millisecond-contact time reactors. Journal of Catalysis, 2005. 235: p. 18-27.

31. Salge, J.R., G.A. Deluga, and L.D. Schmidt, Catalytic partial oxidation of ethanol over noble metal catalysts. Journal of Catalysis, 2005. 235: p. 69-78.

32. Mattos, L.V. and F.B. Noronha, Partial oxidation of ethanol on supported Pt catalysts. Journal of Power Sources, 2005. 145: p. 10-15.

33. Espinosa, L.A., et al., Mechanistic aspects of hydrogen production by partial oxidation of methanol over Cu/ZnO catalysts. Topics in Catalysis, 2003. 22(3-4): p. 245-251.

34. Subramanian, R. and L.D. Schmidt, Renewable Olefins from Biodiesel by Autothermal Reforming. Angewandte Chemie International Edition, 2005. 44: p. 302-305.

35. Leclerc, C.A., J.M. Redenius, and L.D. Schmidt, Fast lightoff of millisecond reactors. Catalysis Letters, 2001. 79(1-4): p. 39-44.

36. Dauenhauer, P.J., J.R. Salge, and L.D. Schmidt, Renewable hydrogen by autothermal steam reforming of volatile carbohydrates. Journal of Catalysis, 2006. 244: p. 238-247. 
37. Lattner, J.R. and M.P. Harold, Autothermal reforming of methanol: Experiments and modeling. Catalysis Today, 2007. 120: p. 78-89.

38. Kang, I. and J. Bae, Autothermal reforming study of diesel for fuel cell application. Journal of Power Sources, 2006. 159: p. 1283-1290.

39. Dreyer, B.J., et al., Autothermal steam reforming of higher hydrocarbons: n-Decane, n-hexadecane, and JP-8. Applied Catalysis A: General, 2006. 307: p. 184-194.

40. Qi, A., et al., Autothermal reforming of n-octane on Ru-based catalysts. Applied Catalysis A: General, 2005. 293: p. 71-82.

41. U.S. Department of Energy. Natural Gas. February 8, 2006 [cited December 18, 2006]; Available from: http://www.energy.gov/energysources/naturalgas.htm.

42. Energy Information Administration. World Proved Reserves of Oil and Natural Gas, Most Recent Estimates. October 5, 2006 [cited December 18, 2006]; Available from: http://www.eia.doe.gov/emeu/international/reserves.html.

43. Nguyen, B.N.T. and C.A. Leclerc, Metal oxides as combustion catalysts for a stratified, dual bed partial oxidation catalyst. Journal of Power Sources, 2006. 163(2): p. 623-629.

44. Krummenacher, J.J. and L.D. Schmidt, High yields of olefins and hydrogen from decane in short contact time reactors: hodium versus platinum. Journal of 
Catalysis, 2004. 222: p. 429-238.

45. Huff, M., P.M. Torniainen, and L.D. Schmidt, Partial oxidation of alkanes over noble metal-coated monoliths. Catalysis Today, 1994. 21: p. 113-128.

46. Huang, T.J. and S.W. Wang, Hydrogen production via partial oxidation of methanol over copper-zinc catalysts. Applied Catalysis, 1986. 24: p. 287-297.

47. Alejo, L., et al., Partial oxidation of methanol to produce hydrogen over Cu-Zn-based catalysts. Applied Catalysis A: General, 1997. 162: p. 281-297.

48. Cubeiro, M.L. and J.L.G. Fierro, Partial oxidation of methanol over supported palladium catalysts. Applied Catalysis A: General, 1998. 168: p. 307322.

49. Grob, R.L. and E.F. Barry, Modem Practice of Gas Chromatography. Fourth ed. 2004: Wiley. 1064.

50. Kim, J.H., et al., Co-solvent Assisted Spray Pyrolysis for the Generation of Metal Particles. Journal of Materials Research, 2003. 18(7): p. 1614-1622.

51. Bunluesin, T., H. Cordatos, and R.J. Gorte, A Study of CO Oxidation Kinetics on Rh/Ceria. Journal of Catalysis, 1995. 157: p. 222-226.

52. Cordatos, H., et al., Effect of Ceria Structure on Oxygen Migration for Rh/Ceria Catalysts. Journal of Physical Chemistry, 1996. 100: p. 785-789.

53. Wheeler, C., et al., The water-gas-shift reaction at short contact times. 
Journal of Catalysis, 2004. 223: p. 191-199.

54. Wanat, E.C., K. Venkataraman, and L.D. Schmidt, Steam reforming and water-gas shift of ethanol on $R h$ and $R h-C e$ catalysts in a catalytic wall reactor. Applied Catalysis A: General, 2004. 276: p. 155-162.

55. Basini, L., Fuel rich catalytic combustion: Principles and technological developments in short contact times (SCT) catalytic processes. Catalysis Today, 2006. 117: p. 384-393.

56. Horn, R., et al., Spatial and temporal profiles in millisecond partial oxidation processes. Catalysis Letters, 2006. 110(3-4): p. 169-178. 


\section{Appendix I: Fuel Injector Calibration Curve}

The figure below represents a sample calibration curve for the fuel injector. The fuel tank was pressurized to $3 \mathrm{psig}(122 \mathrm{kPa})$ and the fuel injector's frequency was $4 \mathrm{~Hz}$.

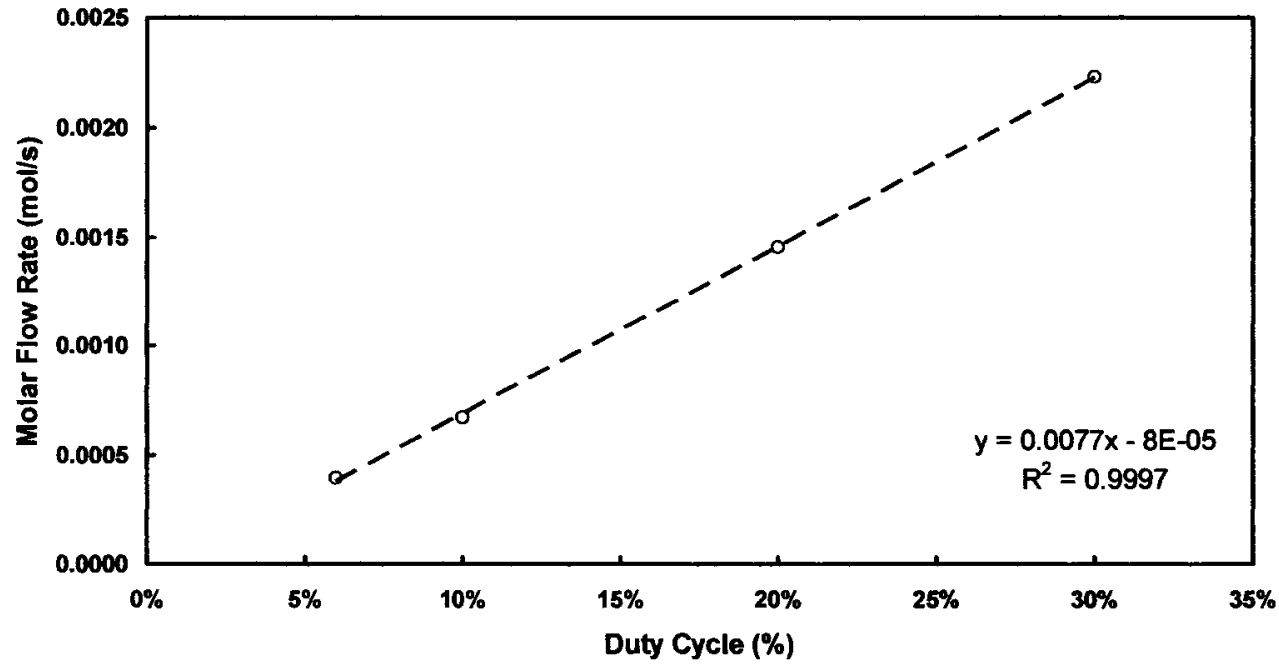




\section{Appendix II: Biodiesel Data}

The following figures are the temperature, conversion and selectivities data from Subramanian's publication [34]. In that work, the CPO of biodiesel is compared to the CPO of hexadecane.

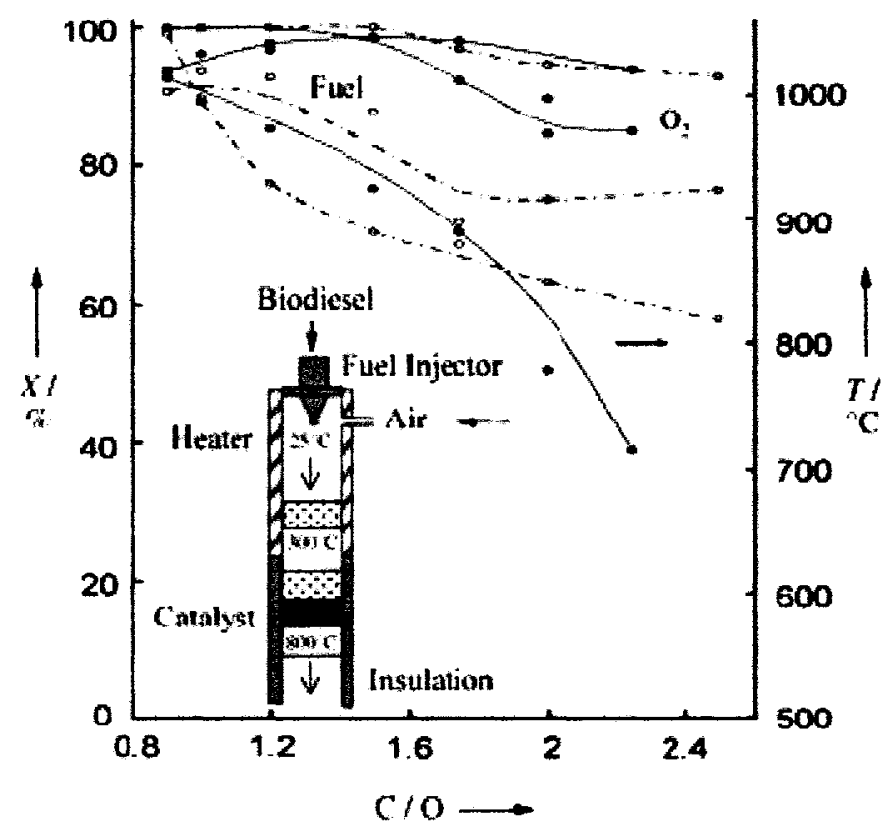

The figure above illustrates the response of the reactor temperature, fuel conversion, and oxygen conversion with respect to the $\mathrm{C} / \mathrm{O}$ ratio. The closed symbols and solid curves denote the data from the CPO of biodiesel while the open symbols and broken lines represent the hexadecane data. From the bottom, the first two curves represent the reactor temperatures for the CPO of biodiesel and hexadecane. The next two curves are the fuel conversions and the two upper curves denote the oxygen conversions. 


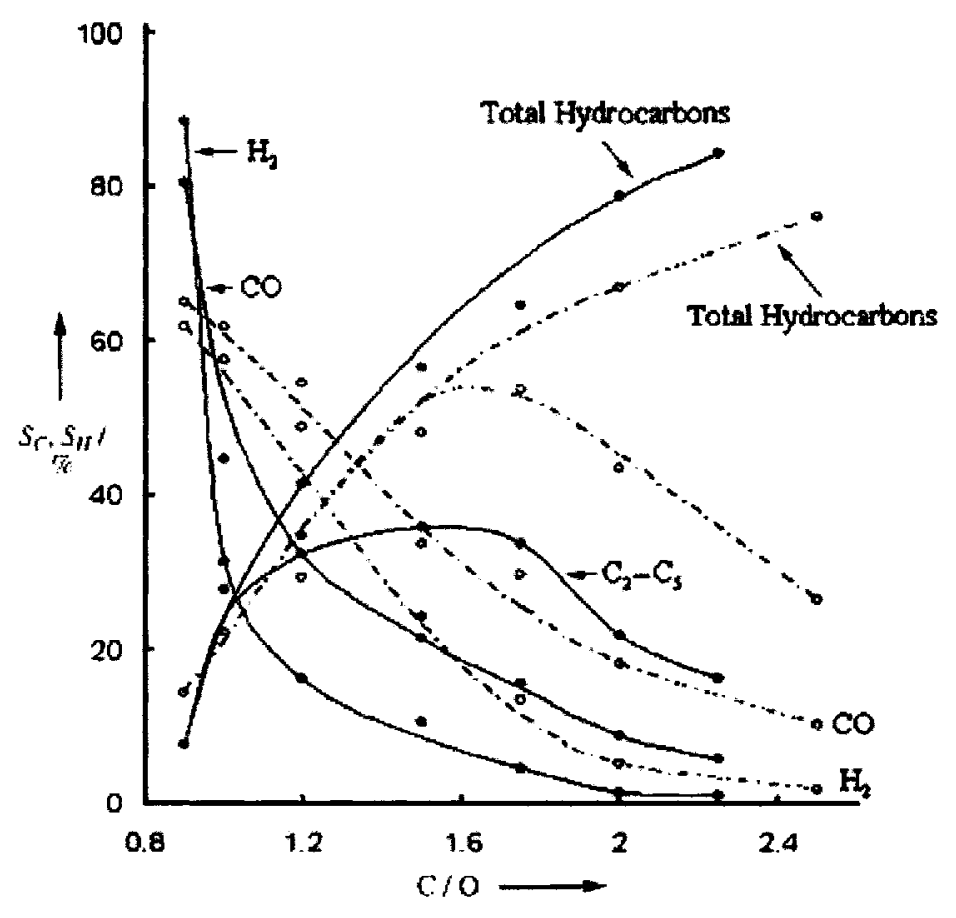

The figure above shows the selectivities for major products $\left(\mathrm{H}_{2}, \mathrm{CO}, \mathrm{C}_{2}-\mathrm{C}_{5}\right.$ hydrocarbons, and total hydrocarbons) plotted against the $\mathrm{C} / \mathrm{O}$ ratios. 